\section{CONTRACTOR REPORT}

SAND95-2571

Unlimited Release

UC-721

\section{RECEIVED}

MAY 151996

OSTI

\title{
Probability, Conditional Probability and Complementary Cumulative Distribution Functions in Performance Assessment for Radioactive Waste Disposal
}

J. C. Helton

Department of Mathematics

Arizona State University

Tempe, AZ 85287-1804

Prepared by

Sandia National Laboratories

Albuquerque, New Mexico 87185 and Livermore, California 94550

for the United States Department of Energy

under Contract DE-AC04-94AL85000

Approved for public release; distribution is unlimited.

Printed March 1996 
Issued by Sandia National Laboratories, operated for the United States Department of Energy by Sandia Corporation.

NOTICE: This report was prepared as an account of work sponsored by an agency of the United States Government. Neither the United States Government nor any agency thereof, nor any of their employees, nor any of their contractors, subcontractors, or their employees, makes any warranty, express or implied, or assumes any legal liablity or responsibility for the accuracy, completeness, or usefulness of any information, apparatus, product, or process disclosed, or represents that its use would not infringe privately owned rights. Reference herein to any specific commercial product, process, or service by trade name, trademark, manufacturer, or otherwise, does not necessarily constitute or imply its endorsement, recommendation, or favoring by the United States Government, any agency thereof or any of their contractors or subcontractors. The views and opinions expressed herein do not necessarily state or reflect those of the United States Government, any agency thereof or any of their contractors.

Printed in the United States of America. This report has been reproduced directly from the best available copy.

Available to DOE and DOE contractors from

Office of Scientific and Technical Information

PO Box 62

Oak Ridge, TN 37831

Prices available from (615) 576-8401, FTS 626-8401

Available to the public from

National Technical Information Service

US Department of Commerce

5285 Port Royal RD

Springfield, VA 22161

NTIS price codes

Printed copy: A04

Microfiche copy: A01 


\title{
Probability, Conditional Probability and Complementary Cumulative Distribution Functions in Performance Assessment for Radioactive Waste Disposal
}

\author{
J. C. Helton \\ Department of Mathematics \\ Arizona State University \\ Tempe, AZ 85287-1804
}

\begin{abstract}
A formal description of the structure of several recent performance assessments (PAs) for the Waste Isolation Pilot Plant (WIPP) is given in terms of the following three components: a probability space $\left(\mathcal{S}_{s t}, \delta_{s t}, p_{s t}\right)$ for stochastic uncertainty, a probability space $\left(\delta_{s u}, \delta_{s u}, p_{s u}\right)$ for subjective uncertainty and a function (i.e., a random variable) defined on the product space associated with $\left(\delta_{s t}, \delta_{s t}, p_{s t}\right)$ and $\left(\mathcal{S}_{s u}, \delta_{s u}, p_{s u}\right)$. The explicit recognition of the existence of these three components allows a careful description of the use of probability, conditional probability and complementary cumulative distribution functions within the WIPP PA. This usage is illustrated in the context of the U.S. Environmental Protection Agency's standard for the geologic disposal of radioactive waste (40 CFR 191, Subpart B). The paradigm described in this presentation can also be used to impose a logically consistent structure on PAs for other complex systems.
\end{abstract}




\section{ACKNOWLEDGMENT}

Review of this presentation was provided by M.G. Marietta and M.S. Tierney of Sandia National Laboratories and is gratefully acknowledged. Further, this presentation would not have been possible without the diligent and highquality work of the many members of the 1991 and 1992 WIPP PA teams, including D.R. Anderson, B.L. Baker, J.E. Bean, J.W. Berglund, W. Beyeler, K. Economy, J.W. Garner, S.C. Hora, H.J. Iuzzolino, P. Knupp, M.G. Marietta, J. Rath, R.P. Rechard, P.J. Roache, D.K. Rudeen, K. Salari, J.D. Schreiber, P.N. Swift, M.S. Tierney, and P. Vaughn. Editorial support was provided by Tech Reps, Inc., with special thanks to H. Olmstead, J. Ripple, and D. Sessions. Work performed for Sandia National Laboratories and the U.S. Department of Energy under contract number DE-AC04-94AL85000. However, the views and ideas expressed in this presentation are the authors' and should not be interpreted as expressing any position or policy by the sponsors. 


\section{CONTENTS}

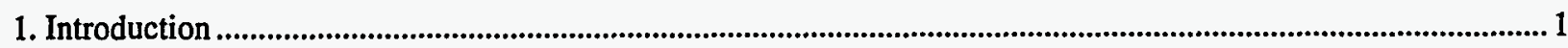

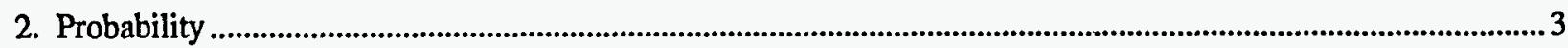

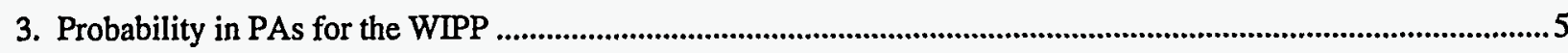

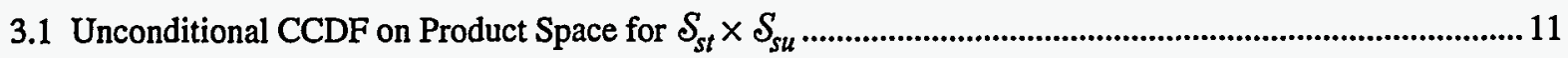

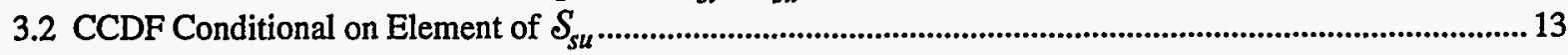

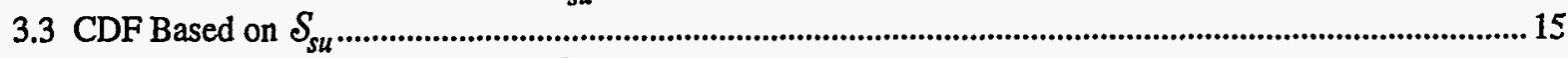

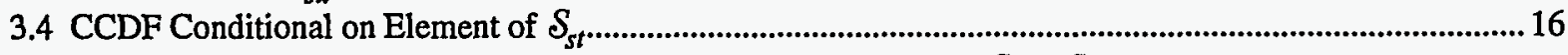

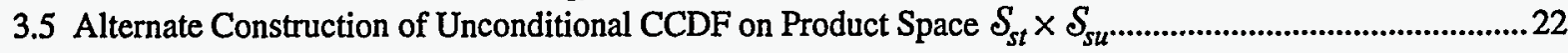

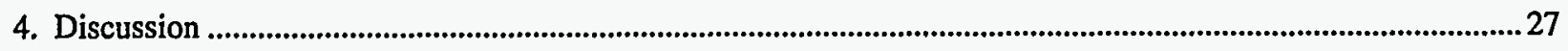

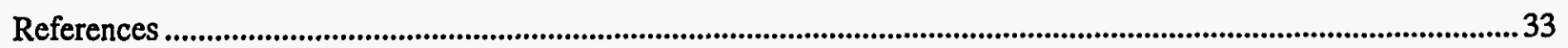




\section{Figures}

Figure

1. Comparison of CCDF for normalized release to the accessible environment with boundary line specified in 191.13(a).

2. Computer programs used in 1991 WIPP PA.

3. Original (unconditional) CCDFs and CCDFs conditional on one or more drilling intrusions for release to the accessible environment due to groundwater transport and release to the accessible environment due to cuttings removal for sample element 46 in 19

4. Distribution of CCDFs for normalized release to the accessible environment including both cuttings removal and groundwater transport with gas generation in the repository and a dual-porosity transport model in the Culebra Dolomite

5. Mean and percentile curves for distribution of CCDFs shown in Fig. 4

6. Estimated CDFs for exceedance probabilities associated with normalized releases to the accessible environment of $R=0.001,0.01$ and 0.1 in Fig. 4

7. Complementary cumulative distribution functions for normalized release to the accessible environment due to groundwater transport conditional on the occurrence of individual elements of $S_{s t}$

8. Alternative summary of CCDFs in Fig. 7 with box plots

9. Construction of Unconditional CCDF on $S_{s t} \times S_{s u}$ by Vertically Averaging CCDFs Conditional on the Occurrence of Elements of $\mathcal{S}_{s t}$

\section{Tables}

Table

1. Examples of Imprecisely Known Variables Considered in 1991 WIPP PA .9

2. Definition of Density Functions for $\left(\mathcal{S}_{s u}, \delta_{s u}, p_{s u}\right),\left(\mathcal{S}_{s t}, \delta_{s t}, p_{s t}\right)$ and $(\mathcal{S}, \ell, p)$ 10 


\section{Introduction}

The importance of an appropriate treatment of uncertainty in performance assessments (PAs) for complex systems is now widely recognized. ${ }^{1-19}$ In particular, analyses for most complex systems such as chemical plants, nuclear power stations, radioactive waste disposal facilities and human populations involve two types of uncertainty: stochastic uncertainty and subjective uncertainty. Stochastic uncertainty arises because the system under study can behave in many different ways and is thus a property of the system. Subjective uncertainty arises from a lack of knowledge about the system and is thus a property of the analysts performing the study. Commonly used terminology for these two types of uncertainty includes aleatory, type A, irreducible and variability as alternatives to the designation stochastic and epistemic, type $\mathrm{B}$, reducible and state of knowledge as alternatives to the designation subjective. Performance assessments must be carefully designed and implemented to maintain a distinction between stochastic and subjective uncertainty. Otherwise, the effects of these two types of uncertainty become commingled in a way that makes it difficult to draw useful insights from the analysis.

Probability is typically used to characterize both stochastic and subjective uncertainty (e.g., see the three analyses summarized in Ref. 20). Indeed, the use of probability is a fundamental part of PA for a complex system, with the result that PA is also referred to as probabilistic risk assessment (PRA). Yet, when the documentation of most PAs is examined, little is typically found that is suggestive of the conceptual material covered in a textbook on probability. This is unfortunate because having a clear conceptual model for the probabilistic basis of an analysis helps in understanding the design and implementation of the analysis, in avoiding conceptual errors, and in relating analysis procedures to similar procedures used in other contexts.

The purpose of this presentation is to provide a formal probabilistic description of a PA involving stochastic and subjective uncertainty. This description will be given in the context of several recent PAs for the Waste Isolation Pilot Plant (WIPP). ${ }^{21-29}$ However, the underlying concepts and associated structure are relevant to PAs for any system that involves both stochastic and subjective uncertainty. 
This page intentionally left blank. 


\section{Probability}

Probability is more than a number between 0 and 1 . Rather, there are three elements in the development of probability: (1) a set $S$ that contains everything that could occur for the particular "universe" under construction, (2) a suitably restricted set $\&$ of subsets of $\mathcal{S}$, called a Borel or $\sigma$-algebra, and (3) a function $p$ defined for elements of $\&$ that actually defines probability. ${ }^{30-31}$ In particular, $\&$ has the properties that $(1)$ if $\varepsilon \in \mathscr{\&}$, then $\varepsilon^{c} \in \mathcal{\&}$, where the superscript $c$ is used to denote the complement of $\mathcal{E}$ and (2) if $\left\{\varepsilon_{i}\right\}$ is a countable collection of elements of $\delta$, then $\cup_{i} \xi_{i}$ and $\cap_{i} \xi_{i}$ are also elements of $\mathscr{\ell}$, and $p$ has the properties that (1) $p(\mathcal{S})=1$, (2) if $\mathcal{E} \in \mathcal{L}$, then $0 \leq p(\mathcal{E}) \leq 1$, and (3) if $\mathcal{E}_{1}, \varepsilon_{2}, \ldots$ is a sequence of disjoint sets from $\&$ (i.e., $\varepsilon_{i} \cap \varepsilon_{j}=\phi$ if $i \neq j$ ), then $p\left(\cup_{i} \varepsilon_{i}\right)=\Sigma_{i} p\left(\xi_{i}\right)$. The triple $(\mathcal{S}, \mathcal{S}, p)$ is called a probability space. In the terminology of probability theory, $S$ is the sample space, the elements of $S$ are elementary events, and the subsets of $S$ contained in $\delta$ are events. In most applied problems, the function $p$ defined on $\mathscr{\&}$ is replaced by a density function $d$ such that, if $\mathcal{E} \in \mathscr{L}$, then

$$
p(\varepsilon)=\int_{\varepsilon} d(\mathbf{x}) d V
$$

In a careful development of probability, the preceding integral would be a Lebesgue integral, but for our purposes it can be assumed to be the Riemann integral of elementary calculus. The properties of the set $\mathscr{b}$ enter into the formal development of the concept of integration over $S$. The notation $d V$ is used in Eq. (1) because $S$ is multidimensional (e.g., $S \subset R^{n}$ ) in most problems of interest.

Problems involving probability usually relate to the behavior of a function $f$ defined on the sample space $S$ associated with a probability space $(\mathcal{S}, \delta, p)$. For example, the expected value of $f$ is given by

$$
E(f)=\int_{S} f(\mathbf{x}) d(\mathbf{x}) d V
$$

Similarly, the complementary cumulative distribution function (CCDF) associated with $f$ is given by

$$
C C D F(R)=\int_{\mathcal{S}} \delta_{R}[f(\mathbf{x})] d(\mathbf{x}) d V
$$

where

$$
\delta_{R}[z]= \begin{cases}1 & \text { if } z>R \\ 0 & \text { if } z \leq R\end{cases}
$$

and $C C D F(R)$ is the probability that a value of $R$ will be exceeded by $f$. In an unfortunate but widely-used terminology, $f$ is referred to as a random variable. 
The CCDF defined in Eq. (3) is defined over the entire sample space $\mathcal{S}$. It is also possible to define CCDFs conditional on the occurrence of subsets of $\mathcal{S}$. In particular, the CCDF associated with $f$ conditional on the occurrence of a subset $\mathcal{E}$ of $S$ is given by

$$
C C D F(R \mid \mathcal{E})=\int_{\mathcal{E}} \delta_{R}[f(\mathbf{x})] d(\mathbf{x}) d V / \int_{\mathcal{E}} d(\mathbf{x}) d V
$$

where $\delta_{R}$ is defined in Eq. (4) and $C C D F(R \mid \mathcal{E})$ is the probability that a value of $R$ will be exceeded by $f$ given that consideration is restricted to the set $\mathcal{E}$ The probabilities $C C D F(R \mid \mathcal{E})$ are conditional probabilities because of the restriction of consideration to the subset $\mathcal{E}$ of $\mathcal{S}$.

An additional important concept that arises in PAs for complex systems is that of a product space. Many problems involve more than one probability space. For example, two probability spaces $\left(\mathcal{S}_{1}, \ell_{1}, p_{1}\right)$ and $\left(\mathcal{S}_{2}, \ell_{2}\right.$, $\left.p_{2}\right)$ might be involved in the formulation of a problem. Then, a third probability space $(\mathcal{S}, \mathcal{\&}, p)$ can be obtained by combining $\left(S_{1}, \ell_{1}, p_{1}\right)$ and $\left(S_{2}, \ell_{2}, p_{2}\right)$, where

$$
\begin{aligned}
\mathcal{S} & =\mathcal{S}_{1} \times \mathcal{S}_{2}=\left\{\left[\mathrm{x}_{1}, \mathrm{x}_{2}\right]: \mathrm{x}_{1} \in \mathcal{S}_{1}, \mathrm{x}_{2} \in \mathcal{S}_{2}\right\}, \\
\mathscr{\delta} & =\mathscr{\delta}_{1} \times \mathscr{\delta}_{2}=\left\{\mathcal{E}: \mathcal{E}=\mathcal{E}_{1} \times \mathcal{E}_{2}, \text { where } \mathcal{E}_{1} \in \delta_{1}, \varepsilon_{2} \in \delta_{2}\right\}, \\
p(\mathcal{E}) & =p_{1}\left(\mathcal{E}_{1}\right) p_{2}\left(\mathcal{E}_{2}\right) \text { for } \mathcal{E}=\varepsilon_{1} \times \mathcal{E}_{2} .
\end{aligned}
$$

The definition of $p(\mathcal{E})$ in Eq. (8) implies that $\left(\mathcal{S}_{1}, \delta_{1}, p_{1}\right)$ and $\left(\mathcal{S}_{2}, \delta_{2}, p_{2}\right)$ are independent in the sense that the occurrence of elements of $S_{1}$ has no effect on the occurrence of elements of $S_{2}$ and vice versa. If such is not the case, then more involved relationships are required to define $p$. 


\section{Probability in PAs for the WIPP}

Now that a few basic ideas from probability have been introduced, the use of probability in PAs for complex systems is considered. This usage will be motivated and illustrated by procedures used in several recent PAs for the WIPP (i.e., in $1991^{21-24}$ and $1992^{25-29}$ ). The use of probability in these PAs derives from the EPA Containment Requirement 40 CFR $191.13,33,34$ which follows:

$\S 191.13$ Containment Requirements.

(a) Disposal systems for spent nuclear fuel or high-level or transuranic radioactive wastes shall be designed to provide a reasonable expectation, based upon performance assessments, that cumulative releases of radionuclides to the accessible environment for 10,000 years after disposal from all significant processes and events that may affect the disposal system shall:

(1) Have a likelihood of less than one chance in 10 of exceeding the quantities calculated according to Table 1 (Appendix A); and

(2) Have a likelihood of less than one chance in 1,000 of exceeding ten times the quantities calculated according to Table 1 (Appendix A).

(b) Performance assessments need not provide complete assurance that the requirements of 191.13(a) will be met. Because of the long time period involved and the nature of the events and processes of interest, there will inevitably be substantial uncertainties in projecting disposal system performance. Proof of the future performance of a disposal system is not to be had in the ordinary sense of the word in situations that deal with much shorter time frames. Instead, what is required is a reasonable expectation, on the basis of the record before the implementing agency, that compliance with 191.13(a) will be achieved.

Containment Requirement 191.13(a) requires that the CCDF for normalized release to the accessible environment fall below a boundary line ${ }^{35-38}$ defined by the points $(0.1,1)$ and $(0.001,10)$ as indicated in Fig 1 . Construction of this CCDF requires a probability space. In the WIPP PA, this probability space is assumed to derive from various disruptive events that conceivably could occur at the WIPP over the next 10,000 yr. The defining character of these events is that their occurrence involves a relatively rapid change in conditions at the WIPP (e.g., volcanism, meteor impact, drilling intrusions, ...). In the WIPP PA, as in many other analyses, the uncertainty indtroduced by the possible occurrence of such disruptions is referred to as stochastic uncertainty and is characterized by a probability space $\left(\mathcal{S}_{s t}, \delta_{s t}, p_{s t}\right)$.

Review work has indicated that drilling intrusions are the only disruptions at the WIPP with sufficient probability to be relevant to assessing compliance with 191.13(a) (Ref. 21, Chapt. 4). Therefore, the probability space $\left(S_{s t}, \delta_{s t}, p_{s t}\right)$ for stochastic uncertainty is used to characterize the occurrence of drilling intrusions. In the computational implementation of recent PAs for the WIPP, the elements $\mathbf{x}_{s t}$ of $\delta_{s t}$ have been vectors of the form

$$
\mathbf{x}_{s t}=\left[t_{1}, x_{1}, l_{1}, t_{2}, x_{2}, l_{2}, \ldots, t_{n}, x_{n}, l_{n}, 0,0,0, \ldots\right],
$$




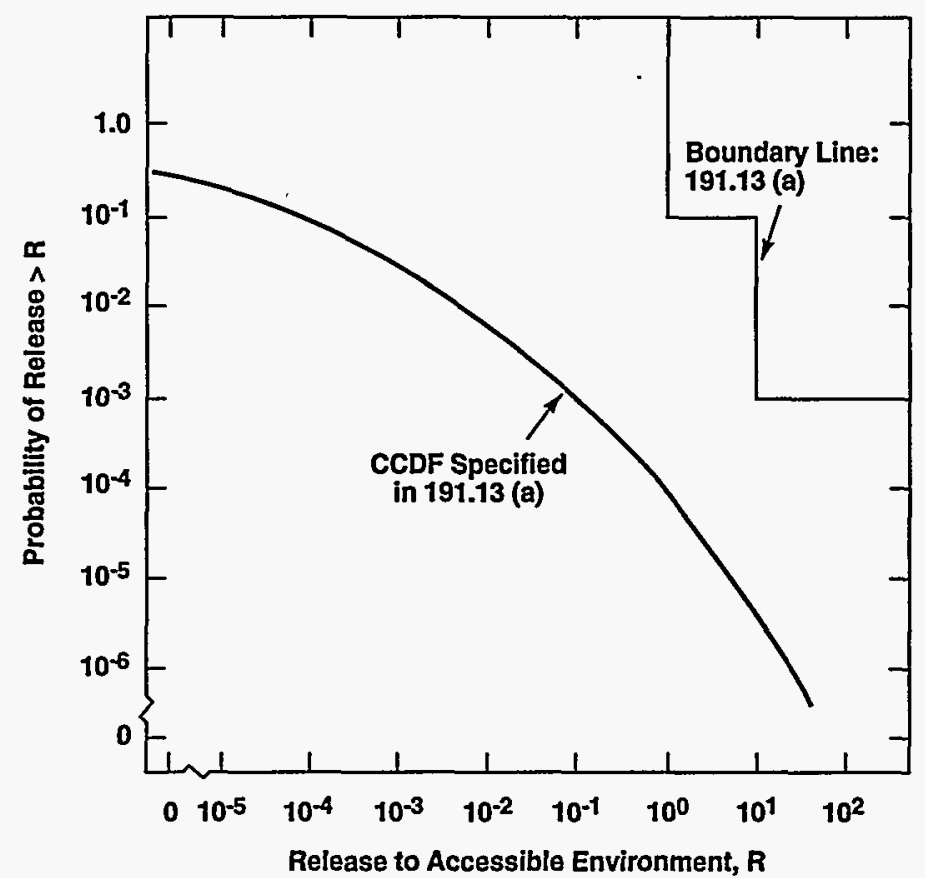

TRI-6342-730-11

Fig. 1. Comparison of CCDF for normalized release to the accessible environment with boundary line specified in 191.13(a).

where $t_{i}$ is the time of the $i^{\text {th }}$ drilling intrusion, $x_{i}$ is the location of the $i^{\text {th }}$ drilling intrusion, $l_{i}$ is the activity level of waste penetrated by the $i^{\text {th }}$ drilling intrusion, and $n$ is the number of drilling intrusions. The function $p_{s t}$ is defined in terms of the rate constant $\lambda$ in a Poisson model for drilling intrusions, the area of pressurized brine beneath the waste panels, and the repository area occupied by waste of each activity level. 39,40 Given the definition of $\mathbf{x}_{s t}$ in Eq. (9), $\mathcal{S}_{s t}$ is a subset of $R^{\infty}$. However, because of upper bounds placed on $\lambda, n$ has been assumed to satisfy the bound $n \leq n B H$ in recent PAs for the WIPP, in which case $\mathcal{S}_{s t}$ is a subset of $R^{3 n B H}$ and, as an example, a subset of $R^{30}$ if $n B H=10$.

The CCDF specified in 191.13(a) is obtained by integrating over $\mathcal{S}_{s t}$ as indicated in Eq. (3). Specifically, the $\mathrm{CCDF}$ for comparison with the EPA release limits is given by

$$
\begin{aligned}
C C D F(R) & =\int_{S_{s t}} \delta_{R}\left[f\left(\mathbf{x}_{s t}\right)\right] d_{s t}\left(\mathbf{x}_{s t}\right) d V_{s t} \\
& \doteq \sum_{i=1}^{n S} \delta_{R}\left[f\left(\mathbf{x}_{s t, i}\right)\right] p_{s t}\left(S_{s t, i}\right)
\end{aligned}
$$

where $R$ corresponds to normalized release to the accessible environment, the function $f$ corresponds to the combined operation of models of the form indicated in Fig. 2 to predict the normalized release associated with an element $\mathbf{x}_{s t}$ 


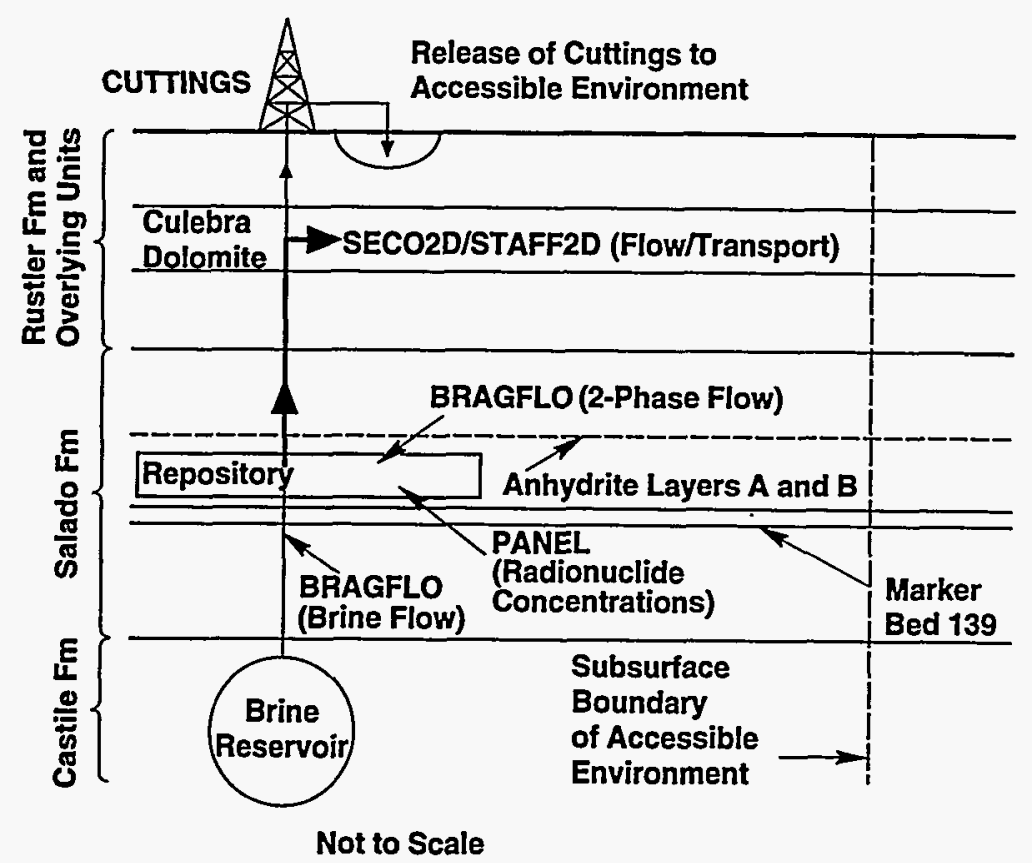

TRI-6342-93-11

Fig. 2. Computer programs used in 1991 WIPP PA. Additional information on the individual programs is available as indicated: BRAGFLO (Ref. 22, Chapt. 5; Ref. 41, Sect. 3.1), CUTTINGS (Ref. 22, Chapt. 7; Ref. 41, Sect. 3.5; Ref. 42), PANEL (Ref. 22, Chapt. 5; Ref. 41, Sect. 3.2), SECO2D (Ref. 22, Chapt. 6; Ref. 41, Sect. 3.3; Ref. 43), STAFF2D (Ref. 22, Chapt. 6; Ref. 41, Sect. 3.4; Ref. 44).

of $S_{s t,} \cup_{i} S_{s t, i}=S_{s t}, S_{s t, i} \cap S_{s t, j}=\phi$ if $i \neq j$, and $x_{s t, i} \in S_{s t, i}$. The approximation to the integral in Eq. (1) indicated in Eq. (11) is calculated by the program CCDFPERM ${ }^{40}$ in recent PAs for the WIPP.

Once $\left(\mathcal{S}_{s t}, \mathscr{\delta}_{s t}, p_{s t}\right)$ and $f$ have been developed, the first of several types of conditional CCDFs is possible. In particular, a CCDF conditional on the occurrence of a specific subset $\mathcal{E}$ of $\mathcal{S}_{s t}$ can be determined. For example, let $\varepsilon_{1}$ be defined by

$$
\varepsilon_{1}=\left\{\mathbf{x}_{s t}: \mathbf{x}_{s t} \in \mathcal{S}_{s t} \text { and involves one or more drilling intrusions }\right\} \text {, }
$$

which is equivalent to defining $\mathcal{E}_{1}$ to be the set of all vectors of the form defined in Eq. (9) with $n \geq 1$. The corresponding conditional CCDF is given by

$$
C C D F\left(R \mid \varepsilon_{1}\right)=\int_{\mathcal{E}_{1}} \delta_{R}\left[f\left(\mathbf{x}_{s t}\right)\right] d_{s t}\left(\mathbf{x}_{s t}\right) d V_{s t} / \int_{\mathcal{E}_{1}} d_{s t}\left(\mathbf{x}_{s t}\right) d V_{s t}
$$

where $C C D F\left(R \mid \mathcal{E}_{1}\right)$ is the conditional probability of exceeding a normalized release of size $R$ given that at least one drilling intrusion has occurred. Examples of CCDFs conditional on the set $\varepsilon_{1}$ in Eq. (12) are shown in Fig. 3. 


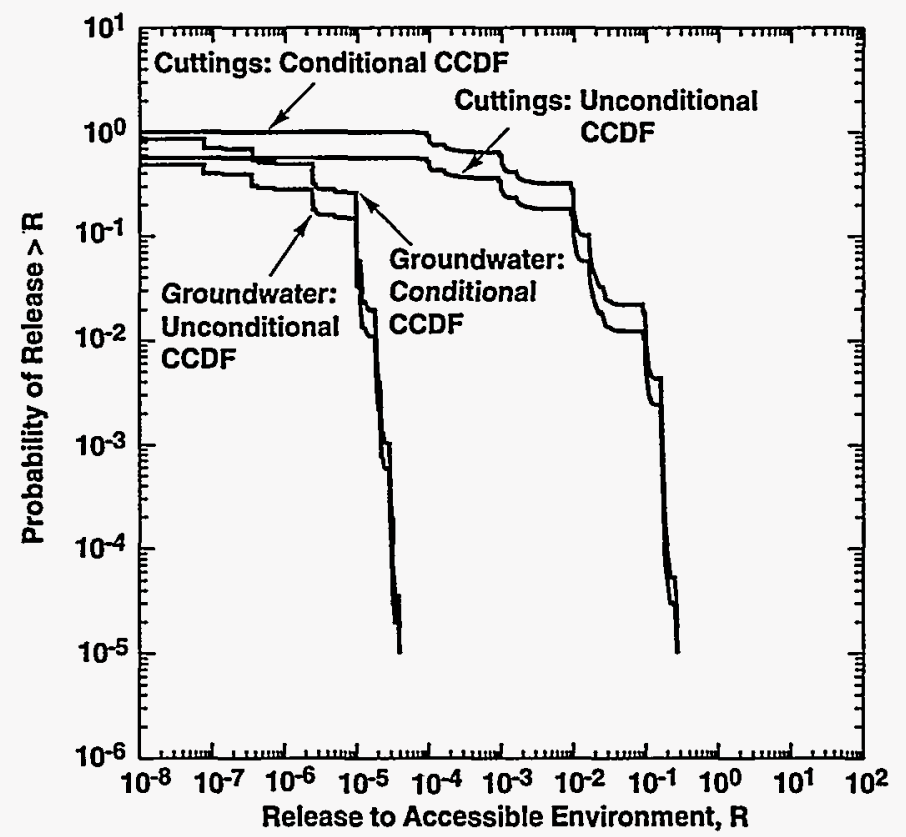

TRI-6342-4346-0

Fig. 3. Original (unconditional) CCDFs and CCDFs conditional on one or more drilling intrusions (i.e., on the set $\mathcal{E}_{1}$ in Eq. (12)) for release to the accessible environment due to groundwater transport and release to the accessible environment due to cuttings removal for sample element 46 in 1991 WIPP PA.

If there was no uncertainty as to how the function $f$ and density $d_{s t}$ in Eq. (10) should be defined, then the CCDF required in 191.13(a) could be calculated and compared with the specified boundary line. With complete certainty, 191.13(a) would either be met or not met, and there would be no additional uncertainty to be considered in the analysis. However, this type of certainty never exists in an analysis for a complex system, which is where 191.13(b) enters the analysis and leads to an additional probability space.

Containment Requirement 191.13(b) requires a "reasonable expectation" that compliance with 191.13(a) will be achieved. The goal in recent PAs for the WIPP has been to assess this reasonable expectation on the basis of the effects that fixed, but poorly known, quantities have on the location of the CCDF specified in 191.13(a). To this end, the function $f$ and density $d_{s t}$ in Eq. (10) were developed so that $f\left(\mathbf{x}_{s t}\right)$ and $d_{s t}\left(\mathbf{x}_{s t}\right)$ depend on quantities that are believed to have fixed values (at least within the resolution of the modeling being used). In other words, $f$ and $d_{s t}$ are treated as being of the form $f\left(\mathbf{x}_{s t}, \mathbf{x}_{s u}\right)$ and $\dot{d}_{s t}\left(\mathbf{x}_{s t} \mid \mathbf{x}_{s u}\right)$, where $\mathbf{x}_{s t} \in \mathcal{S}_{s t}$ and $\mathbf{x}_{s u}$ is a vector of fixed, but poorly known, quantities. Distributions are then assigned to the elements of $\mathbf{x}_{s u}$ to characterize where their true, but unknown, values are believed to be located. In turn, the location of the distribution of CCDFs that results from the uncertainty in $\mathbf{X}_{s u}$ provides a measure of the assurance with which 191.13(a) can be met. The development of distributions for the elements of $x_{s u}$ is still in progress in the WIPP PA, ${ }^{23,27}$ with the result that the PA has not yet arrived at the point where all distributions in use can be viewed a providing representations for where "true, but unknown, values are 
believed to be located." In particular, the analysis is still at a stage where some distributions are assigned primarily to help assess the sensitivity of analysis outcomes to the associated input variable.

Definition of distributions for the elements of $\mathrm{x}_{s u}$ defines the probability space $\left(\mathcal{S}_{s u}, \delta_{s u}, p_{s u}\right)$ for subjective uncertainty. Here, subjective uncertainty is used to designate a lack of knowledge about a fixed, but unknown, quantity. The study of subjective uncertainty is the primary domain of classical statistics, although many analyses for complex systems find that they must rely heavily on expert-review processes ${ }^{45-48}$ to assess subjective uncertainty [i.e., to define $\left(S_{s u}, \delta_{s u}, p_{s u}\right)$ ]. In the 1991 WIPP PA, $\mathbf{x}_{s u}$ contained the 45 variables indicated in Table 1; thus, $S_{s u}$ is a subset of $R^{45}$. For notational ease, integrals over elements of $\phi_{s u}$ will be expressed with the density function $d_{s u}$. Thus,

$$
p(\mathcal{E})=\int_{\mathcal{E}} d_{s u}\left(\mathbf{x}_{s u}\right) d V_{s u}
$$

for $\varepsilon \in \mathscr{S}_{s u}$

Table 1. Examples of Imprecisely Known Variables Considered in 1991 WIPP PA (adapted from Table 3-1 of Ref. 24, App. A of Ref. 41 and Table VIII of Ref. 49, which list all 45 variables considered in the 1991 WIPP PA). The variables indicated in this table and their associated distributions define the probability space $\left(\mathcal{S}_{s u}, \delta_{s u}, p_{s u}\right)$ for subjective uncertainty.

\begin{tabular}{|c|c|c|}
\hline & Variable & Definition \\
\hline 1 & BHPERM & Borehole permeability. Range: $1 \times 10^{-14}$ to $1 \times 10^{-11} \mathrm{~m}^{2}$. Distribution: Lognormal. \\
\hline 2 & BPPRES & $\begin{array}{l}\text { Initial pressure of pressurized brine pocket in Castile Formation: Range: } 1.1 \times 10^{7} \text { to } 2.1 \\
\times 10^{7} \mathrm{~Pa} \text {. Distribution: Piecewise linear. }\end{array}$ \\
\hline 3 & BPSTOR & $\begin{array}{l}\text { Bulk storativity of pressurized brine pocket in Castile Formation: Range: } 2 \times 10^{-2} \text { to } 2 \\
\mathrm{~m}^{3} \text {. Distribution: Lognormal. }\end{array}$ \\
\hline \multirow[t]{3}{*}{4} & BPAREAFR & $\begin{array}{l}\text { Fraction of waste panel area underlain by a pressurized brine pocket (dimensionless). } \\
\text { Range: } 2.5 \times 10^{-1} \text { to } 5.52 \times 10^{-1} \text {. Distribution: Approximately uniform. }\end{array}$ \\
\hline & & - \\
\hline & & $\stackrel{\bullet}{\bullet}$ \\
\hline \multirow[t]{3}{*}{23} & $\angle A M B D A$ & $\begin{array}{l}\text { Rate constant in Poisson model for drilling intrusions. Range: } 0 \text { to } 1.04 \times 10^{-11} \mathrm{~s}^{-1} \text {. } \\
\text { Distribution: Uniform. }\end{array}$ \\
\hline & & - \\
\hline & & \\
\hline 45 & VWOOD & $\begin{array}{l}\text { Fraction of total waste volume that is occupied by IDB (Integrated Data Base) } \\
\text { combustible waste category (dimensionless). Range: } 2.84 \times 10^{-1} \text { to } 4.84 \times 10^{-1} \text {. } \\
\text { Distribution: Normal. }\end{array}$ \\
\hline
\end{tabular}


At this point, the WIPP PA involves two probability spaces, $\left(\delta_{s t}, \delta_{s t}, p_{s t}\right)$ and $\left(\delta_{s u}, \delta_{s u}, p_{s u}\right)$, and the actual object of study becomes the product space $(\mathcal{S}, \mathscr{\&}, p)$ derived from these two individual spaces [see Eqs. (6) - (8)]. Definition of the probability function $p$ associated with this product space is actually more complicated than indicated in Eq. (8) because elements of $\delta_{s u}$ affect the definition of $p_{s t}$. In particular, $p$ has the form

$$
\begin{aligned}
p(\mathcal{E}) & =\int_{\mathcal{E}} d(\mathbf{x}) d V, \quad \mathbf{x}=\left[\mathbf{x}_{s t}, \mathbf{x}_{s u}\right] \\
& =\int_{\mathcal{E}_{s u}}\left[\int_{\mathcal{E}_{s t}} d_{s t}\left(\mathbf{x}_{s t} \mid \mathbf{x}_{s u}\right) d V_{s t}\right] d_{s u}\left(\mathbf{x}_{s u}\right) d V_{s u},
\end{aligned}
$$

where $\mathcal{E}=\mathcal{E}_{s t} \times \mathcal{E}_{s u} \in \mathscr{S}, d$ is the density function associated with $p$, and $d_{s t}$ is now a function of both $\mathbf{x}_{s t}$ and $\mathbf{x}_{s u}$ (Table 2).

Three different CCDFs associated with the product space containing $\mathcal{S}_{s t} \times \mathcal{S}_{s u}$ for normalized release to the accessible environment are presented in PAs for the WIPP: an unconditional CCDF based on the entire product space, a CCDF conditional on the occurrence of a specific element of $\mathcal{S}_{s u}$, and a CCDF conditional on the occurrence of a specific element of $S_{s t}$. In addition, a cumulative distribution function (CDF) based on the probability space $\left(\delta_{s u}, \delta_{s u}, p_{s u}\right)$ also plays an important role. Each of these cases is now discussed.

Table 2. Definition of Density Functions for $\left(\mathcal{S}_{s u}, \delta_{s u}, p_{s u}\right),\left(\mathcal{S}_{s t}, \delta_{s t}, p_{s t}\right)$ and $(\mathcal{S}, \not, p)$.

\section{Density Functions Assumed to be Known}

$$
\begin{aligned}
& d_{s u}\left(\mathbf{x}_{s u}\right)=\text { density function for }\left(\delta_{s u}, \delta_{s u}, p_{s u}\right) \\
& d_{s t}\left(\mathbf{x}_{s t} \mid \mathbf{x}_{s u}\right)=\text { density function for }\left(\mathcal{S}_{s t}, \delta_{s t}, p_{s t}\right) \text { given } \mathbf{x}_{s u}
\end{aligned}
$$

\section{Constructed Density Functions}

$$
\begin{aligned}
d\left(\mathbf{x}_{s t}, \mathbf{x}_{s u}\right) & =\text { density function for }(\mathcal{S}, \&, p) \\
& =d_{s t}\left(\mathbf{x}_{s t} \mid \mathbf{x}_{s u}\right) d_{s u}\left(\mathbf{x}_{s u}\right) \\
d_{s t}\left(\mathbf{x}_{s t}\right) & =\text { density function for }\left(\mathcal{S}_{s t}, \delta_{s t}, p_{s t}\right) \\
& =\int_{S_{s u}} d\left(\mathbf{x}_{s t}, \mathbf{x}_{s u}\right) d V_{s u} \\
& =\int_{\mathcal{S}_{s u}} d_{s t}\left(\mathbf{x}_{s t} \mid \mathbf{x}_{s u}\right) d_{s u}\left(\mathbf{x}_{s u}\right) d V_{s u} \\
d_{s u}\left(\mathbf{x}_{s u} \mid \mathbf{x}_{s t}\right) & =\text { density function for }\left(\mathcal{S}_{s u}, \delta_{s u}, p_{s u}\right) \text { given } \mathbf{x}_{s t} \\
& =d\left(\mathbf{x}_{s t}, \mathbf{x}_{s u}\right) / d_{s t}\left(\mathbf{x}_{s t}\right), d_{s t}\left(\mathbf{x}_{s t}\right) \neq 0 \\
& =d_{s t}\left(\mathbf{x}_{s t} \mid \mathbf{x}_{s u}\right) d_{s u}\left(\mathbf{x}_{s u}\right) / \int_{S_{s u}} d_{s t}\left(\mathbf{x}_{s t} \mid \mathbf{x}_{s u}\right) d_{d u}\left(\mathbf{x}_{s u}\right) d V_{s u}
\end{aligned}
$$




\subsection{Unconditional CCDF on Product Space for $\delta_{s t} \times \delta_{s u}$}

The unconditional CCDF based on the entire product space is given by

$$
\begin{aligned}
C C D F(R) & =\int_{S} \delta_{R}[f(\mathbf{x})] d(\mathbf{x}) d V, S=S_{s t} \times S_{s u}, \mathbf{x}=\left[\mathbf{x}_{s t}, \mathbf{x}_{s u}\right] \\
& =\int_{S_{s u}}\left[\int_{S_{s t}} \delta_{R}\left[f\left(\mathbf{x}_{s t}, \mathbf{x}_{s u}\right)\right] d_{s t}\left(\mathbf{x}_{s t} \mid \mathbf{x}_{s u}\right) d V_{s t}\right] d_{s u}\left(\mathbf{x}_{s u}\right) d V_{s u},
\end{aligned}
$$

where $C C D F(R)$ is the probability that a normalized release of size $R$ will be exceeded. In the 1991 WIPP PA, the function $f$ derives from the combined operation of the CUTTINGS, BRAGFLO, PANEL, SECO2D and STAFF2D models as indicated in Fig. 2; in the 1992 WIPP PA, the STAFF2D model was replaced by the SECOTP model (Ref. 26, App. C; Ref. 28, Chapt. 6). The CCDF in Eq. (16) is designated as the mean CCDF in PAs for the WIPP (see Figs. 4 and 5, with an approximation to the CCDF defined in Eq. (16) appearing in Fig. 5). The reason for the designation "mean CCDF" will be discussed later.

The integral in Eq. (16) is too complicated to be evaluated with a closed-form procedure. Rather, a numerical approximation must be used. In the WIPP PA, a two stage procedure is used to approximate this integral. In the first stage, Monte Carlo techniques are used to approximate the outer integral in Eq. (16). Specifically, a Latin hypercube sample ${ }^{51}$

$$
\mathbf{x}_{s u, k}, k=1,2, \ldots, n L H S
$$

is generated from the sample space $\mathcal{S}_{s u}$ associated with the probability space $\left(\mathcal{S}_{s u}, \mathcal{\delta}_{s u}, p_{s u}\right)$, which leads to the following approximation to $C C D F(R)$ :

$$
C C D F(R) \doteq \sum_{k=1}^{n L H S} \int_{S_{s t}} \delta_{R}\left[f\left(\mathbf{x}_{s t}, \mathbf{x}_{s u, k}\right)\right] d_{s t}\left(\mathbf{x}_{s t} \mid \mathbf{x}_{s u, k}\right) d V_{s t} / n L H S .
$$

In the WIPP PA, the Latin hypercube sample is generated with the LHS program ${ }^{52}$ and the mechanics of performing the indicated summation take place in the CCDFPERM program. ${ }^{40}$ In the second stage of the procedure, the integrals in Eq. (18) are evaluated with an importance sampling procedure (Ref. 53, Sect. 5.4) that involves the subdivision of the sample space $S_{s t}$ associated with the probability space $\left(S_{s t}, \delta_{s t}, p_{s t}\right)$ into a sequence $\delta_{s t, i}, i=1$, $2, \ldots, n S$, of disjoint subsets such that $\cup_{i} S_{s t, i}=S_{s t}$. Although the notation in use does not explicitly indicate it, $\left(S_{s t}\right.$, $\delta_{s t}, p_{s t}$ ) actually changes from sample element to sample element (i.e., is a function of $\mathrm{x}_{s u}$ ) due to the dependence of $p_{s t}$ on variables contained in $\mathbf{x}_{s u}$, with the result that the sets $S_{s t, i}$ and the probabilities $p_{s t}\left(S_{s t, i}\right)$ can also change from sample element to sample element. Once the $S_{s t, i}$ are defined, the approximation to $C C D F(R)$ becomes

$$
C C D F(R) \doteq \sum_{k=1}^{n L H S}\left[\sum_{i=1}^{n S} \delta_{R}\left[f\left(\mathbf{x}_{s t, i}, \mathbf{x}_{s u, k}\right)\right] p_{s t}\left(\delta_{s t, i}\right)\right] / n L H S,
$$




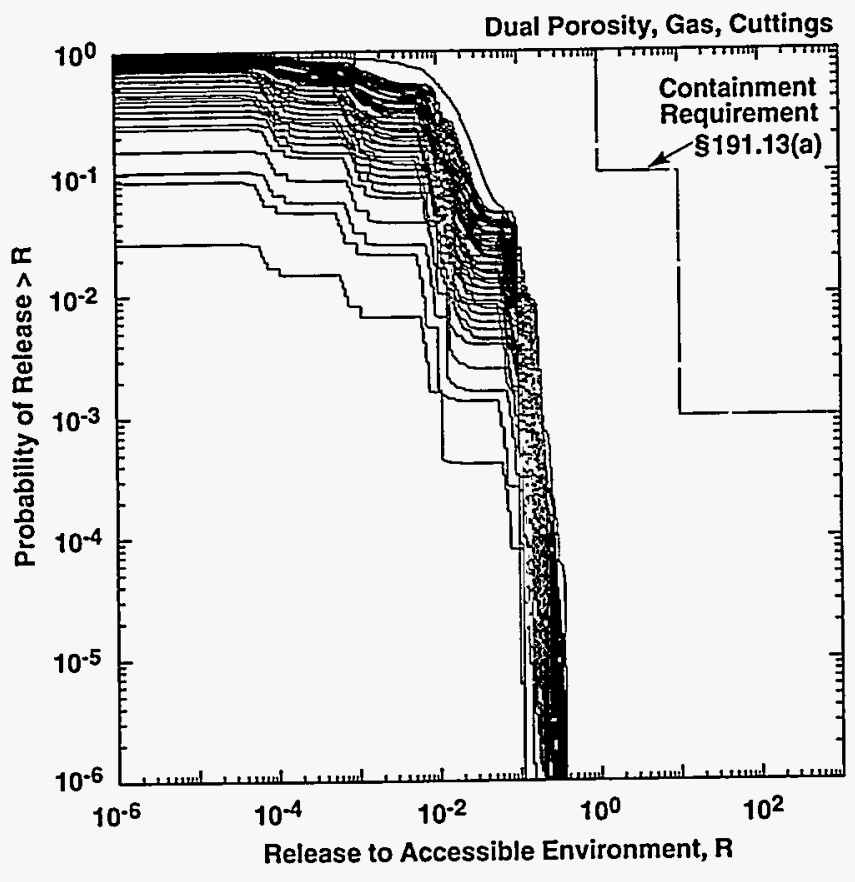

Fig. 4. Distribution of CCDFs for normalized release to the accessible environment including both cuttings removal and groundwater transport with gas generation in the repository and a dual-porosity transport model in the Culebra Dolomite (Ref. 24, Fig. 2.2-2; Ref. 49, Fig. 2).

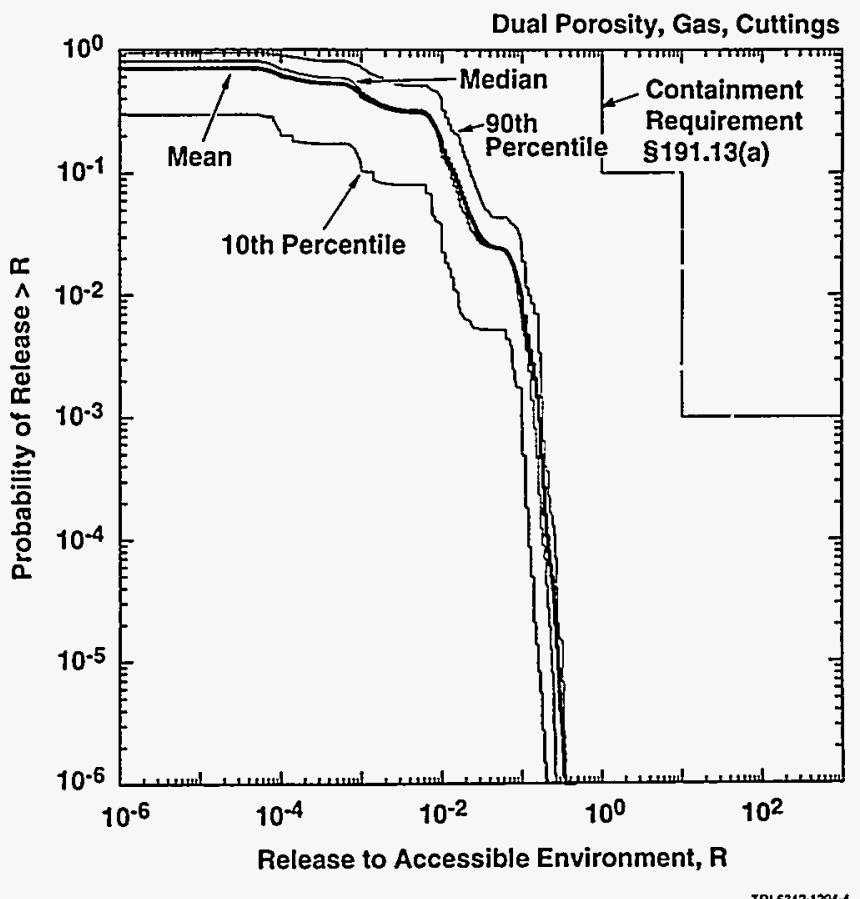

Fig. 5. Mean and percentile curves for distribution of CCDFs shown in Fig. 4 (Ref. 24, Fig. 4.1-1; Ref. 49, Fig. 6). 
where $x_{s t, i} \in S_{s t, i}$ and $p_{s t}\left(S_{s t, i}\right)$ is defined by

$$
p_{s t}\left(\mathcal{S}_{s t, i}\right)=\int_{S_{s t, i}} d_{s t}\left(\mathbf{x}_{s t} \mid \mathbf{x}_{s u, k}\right) d V_{s t}
$$

In terms of implementation, $f\left(\mathbf{x}_{s t}, \mathbf{x}_{s u, k}\right)$ is calculated with CUTTINGS, BRAGFLO, PANEL, SECO2D and STAFF2D for a relatively small number of elements $\mathbf{x}_{s t}$ of $\mathcal{S}_{s t}$; the results for these elements are then used to construct (i.e., estimate) $f\left(\mathbf{x}_{s t, i}, \mathbf{x}_{s u, k}\right)$ for the large number of $\mathbf{x}_{s t, i}$ involved in the summation in Eq. (19). ${ }^{40}$ This construction process takes place in the program CCDFPERM, as does the evaluation of the probability $p_{s t}\left(\mathcal{S}_{s t, i}\right)$ in Eq. (20). The mean CCDF in Fig. 5 was produced by the calculation shown in Eq. (19).

\subsection{CCDF Conditional on Element of $s_{s u}$}

The construction of a CCDF conditional on the occurrence of a specific element of $\mathcal{S}_{s u}$ is now considered. It is useful to begin by considering the more general case of a CCDF conditional on the occurrence of an arbitrary subset $\varepsilon_{s u}$ of $S_{s u}$. The corresponding conditional CCDF for normalized release to the accessible environment has the form shown in Eq. (5), where the probability space under consideration is the product space associated with $\mathcal{S}_{s t} \times \mathcal{S}_{s u}$. As a result, the CCDF is actually conditional on the occurrence of $\delta_{s t} \times \varepsilon_{s u}$. Specifically,

$$
\begin{aligned}
C C D F\left(R \mid S_{s t} \times \mathcal{E}_{s u}\right)= & \int_{\mathcal{S}_{s t} \times \mathcal{E}_{s u}} \delta_{R}[f(\mathbf{x})] d(\mathbf{x}) d V / \int_{\mathcal{S}_{s t} \times \varepsilon_{s u}} d(\mathbf{x}) d V, \mathbf{x}=\left[\mathbf{x}_{s t}, \mathbf{x}_{s u}\right] \\
= & \int_{\mathcal{E}_{s u}} \int_{S_{s t}} \delta_{R}\left[f\left(\mathbf{x}_{s t}, \mathbf{x}_{s u}\right)\right] d_{s t}\left(\mathbf{x}_{s t} \mid \mathbf{x}_{s u}\right) d_{s u}\left(\mathbf{x}_{s u}\right) d V_{s t} d V_{s u} \\
& / \int_{\varepsilon_{s u}} \int_{S_{s t}} d_{s t}\left(\mathbf{x}_{s t} \mid \mathbf{x}_{s u}\right) d_{s u}\left(\mathbf{x}_{s u}\right) d V_{s t} d V_{s u}
\end{aligned}
$$

where $C C D F\left(R \mid S_{s t} \times \mathcal{E}_{s u}\right)$ is the probability that a normalized release of size $R$ will be exceeded conditional on the occurrence of $S_{s t} \times \varepsilon_{s u}$.

For a CCDF conditional on the occurrence of a specific element $\tilde{\mathbf{x}}_{s u}$ of $\delta_{s u}$, the set $\varepsilon_{s u}$ will contain only $\tilde{\mathbf{x}}_{s u}$, with the outcome that the integrals in the numerator and denominator of Eq. (21) will be zero. As a result, Eq. (21) cannot be applied directly to obtain $C C D F\left(R \mid S_{s t} \times\left\{\tilde{\mathbf{x}}_{s u}\right\}\right)$ Instead, the desired probability is obtained by taking the limit of the expression in Eq. (21) as the size of the set $\varepsilon_{s u}$ containing $\tilde{\mathbf{x}}_{s u}$ approaches a volume of zero (i.e., as $\left.V\left(\varepsilon_{s u}\right) \rightarrow 0\right)$. Specifically, $C C D F\left(R \mid S_{s t} \times\left\{\tilde{\mathbf{x}}_{s u}\right\}\right)$ is defined by the limit 


$$
\begin{aligned}
& C C D F\left(R \mid S_{s t} \times\left\{\tilde{\mathbf{x}}_{s t}\right\}\right)=\operatorname{limit}_{V\left(\varepsilon_{s u}\right) \rightarrow 0}\left\{\int_{\mathcal{E}_{s u}} \int_{\mathcal{S}_{s t}} \delta_{R}\left[f\left(\mathbf{x}_{s t}, \mathbf{x}_{s u}\right)\right] d_{s t}\left(\mathbf{x}_{s t} \mid \mathbf{x}_{s u}\right) d_{s u}\left(\mathbf{x}_{s u}\right) d V_{s t} d V_{s u}\right. \\
& \left./ \int_{\varepsilon_{s u}} \int_{S_{s t}} d_{s t}\left(\mathbf{x}_{s t} \mid \mathbf{x}_{s u}\right) d_{s u}\left(\mathbf{x}_{s u}\right) d V_{s t} d V_{s u}\right\} \\
& =\operatorname{limit}_{V\left(\varepsilon_{s u}\right) \rightarrow 0}\left\{\left[\int_{S_{s t}} \delta_{R}\left[f\left(\mathbf{x}_{s t}, \overline{\mathbf{x}}_{s u}\right)\right] d_{s t}\left(\mathbf{x}_{s t} \mid \overline{\mathbf{x}}_{s u}\right) d V_{s t}\right] d_{s u}\left(\overline{\mathbf{x}}_{s u}\right) V\left(\varepsilon_{s u}\right)\right. \\
& \left.I\left[\int_{\mathcal{S}_{s t}} d_{s t}\left(\mathbf{x}_{s t} \mid \hat{\mathbf{x}}_{s u}\right) d V_{s t}\right] d_{s u}\left(\hat{\mathbf{x}}_{s u}\right) V\left(\mathcal{E}_{s u}\right)\right\} \\
& \text { [by mean value theorem with } \overline{\mathbf{x}}_{s u}, \hat{\mathbf{x}}_{s u} \in \varepsilon_{s u} \text { ] } \\
& =\operatorname{limit}_{V\left(\varepsilon_{s u}\right) \rightarrow 0}\left[\int_{S_{s t}} \delta_{R}\left[f\left(\mathbf{x}_{s t}, \overline{\mathbf{x}}_{s u}\right)\right] d_{s t}\left(\mathbf{x}_{s t} \mid \overline{\mathbf{x}}_{s u}\right) d V_{s t}\right]\left[d_{s u}\left(\overline{\mathbf{x}}_{s u}\right) / d_{s u}\left(\hat{\mathbf{x}}_{s u}\right)\right] \\
& =\int_{\mathcal{S}_{s t}} \delta_{R}\left[f\left(\mathbf{x}_{s t}, \tilde{\mathbf{x}}_{s u}\right)\right] d_{s t}\left(\mathbf{x}_{s t} \mid \tilde{\mathbf{x}}_{s u}\right) d V_{s t},
\end{aligned}
$$

provided the functions involved are "reasonably" behaved.

The expression $C C D F\left(R \mid S_{s t} \times\left\{\tilde{\mathbf{x}}_{s u}\right\}\right)$ as defined by the integral in Eq. (22) gives the probability of exceeding a normalized release of size $R$ conditional on the occurrence of the element $\tilde{\mathbf{x}}_{s u}$ of $\mathcal{S}_{s u}$. In PAs for the WIPP, this probability is approximated by

$$
C C D F\left(R \mid \mathcal{S}_{s t} \times\left\{\tilde{\mathbf{x}}_{s u}\right\}\right) \doteq \sum_{i=1}^{n S} \delta_{R}\left[f\left(\mathbf{x}_{s t, i}, \tilde{\mathbf{x}}_{s u}\right)\right] p_{s t}\left(\mathcal{S}_{s t, i}\right)
$$

with use of the same notation as in Eq. (19). In particular, the probability of exceeding a normalized release of size $R$ conditional on the occurrence of a sample element $\mathbf{x}_{s u, k}$ of the form indicated in Eq. (17) is

$$
C C D F\left(R \mid \mathcal{S}_{s t} \times\left\{\mathbf{x}_{s u, k}\right\}\right) \doteq \sum_{i=1}^{n S} \delta_{R}\left[f\left(\mathbf{x}_{s t, i}, \mathbf{x}_{s u, k}\right)\right] p_{s t}\left(\mathcal{S}_{s t, i}\right)
$$

Plots of the resultant CCDFs for the individual sample elements in the 1991 WIPP PA appear in Fig. 4. The calculation indicated in Eq. (24) to obtain the CCDFs in Fig. 4 is performed in the program CCDFPERM. 40

The CCDF discussed in Sect. 3.1 is often referred to as a "mean CCDF" because it can be viewed as the mean of the CCDFs discussed in this section. In particular, the integral for $C C D F\left(R \mid \mathcal{S}_{s t} \times\left\{\tilde{\mathbf{x}}_{s u}\right\}\right)$ in Eq. (22) is the inner integral in Eq. (16). 


\subsection{CDF Based on $\delta_{s u}$}

The expression $C C D F\left(R \mid \mathcal{S}_{s t} \times\left\{\mathrm{x}_{s u}\right\}\right)$ is a function defined on $\mathcal{S}_{s u}$ for each value of $R$. Thus, this expression has a distribution that derives from the probability space $\left(\delta_{s u}, \delta_{s u}, p_{s u}\right)$. For notational reasons, this distribution is best expressed as a cumulative distribution function (CDF). In particular, the probability that $C C D F\left(R \mid S_{s t} \times\left\{\mathrm{x}_{s u}\right\}\right)$ is less than or equal to $p$ is given by

$$
\begin{aligned}
C D F(p, R) & =1-\int_{S_{s u}} \delta_{p}\left[C C D F\left(R \mid S_{s t} \times\left\{\mathbf{x}_{s u}\right\}\right)\right] d\left(\mathbf{x}_{s u}\right) d V_{s u} \\
& =1-\int_{S_{s u}} \delta_{p}\left\{\int_{S_{s t}} \delta_{R}\left[f\left(\mathbf{x}_{s t}, \mathbf{x}_{s u}\right)\right] d_{s t}\left(\mathbf{x}_{s t} \mid \mathbf{x}_{s u}\right) d V_{s t}\right\} d\left(\mathbf{x}_{s u}\right) d V_{s u},
\end{aligned}
$$

where $\delta_{p}$ is defined as indicated in Eq. (4). The CDFs defined by Eq. (25) are characterizing the uncertainty in the exceedance probabilities that are used in comparisons with the boundary line specified in 191.13(a). The probability space $\left(S_{s u}, \delta_{s u}, p_{s u}\right)$ characterizes how well we (i.e., all the analysts involved) know the appropriate values for use in the modeling system employed in a PA for the WIPP. The uncertainty in this input translates into corresponding uncertainty in quantities predicted by the PA. Among these uncertain quantities are the exceedance probabilities associated with normalized releases of different sizes. The CDFs defined by Eq. (25) characterize a degree of belief with respect to where these exceedance probabilities are located and thus provide a measure of the assurance requested in 191.13(b) that 191.13(a) will be met.

As is the case for all integrals over probability spaces in PAs for the WIPP, the integral in Eq. (25) must be approximated numerically. Specifically, the following approximation is used:

$$
C D F(p, R) \doteq 1-\sum_{k=1}^{n L H S} \delta_{p}\left\{\sum_{i=1}^{n S} \delta_{R}\left[f\left(\mathbf{x}_{s t, i}, \mathbf{x}_{s u, k}\right)\right] p_{s t}\left(\mathcal{S}_{s t, i}\right)\right\} / n L H S,
$$

where notation is the same as used in Eq. (19). Further, Eq. (19) provides an approximation to the expected (i.e., mean) value of $\operatorname{CCDF}\left(R \mid \delta_{s t} \times\left\{\mathbf{x}_{s u}\right\}\right)$, where this expectation derives from $\left(\delta_{s u}, \delta_{s u}, p_{s u}\right)$. As an example, the CDFs that result for the results summarized in Fig. 4 and values of $R=0.001,0.01$ and 0.1 are shown in Fig. 6. The preceding procedure for estimating the integral in Eq. (25) for a given value of $R$ is equivalent to determining the number $n E(\leq p)$ of CCDFs that have an exceedance probability less than or equal to $p$ and then defining $C D F(p, R)$ to be $n E(\leq p) / n L H S$. The percentile curves (i.e., $10^{\text {th }}, 50^{\text {th }}$ (median), $90^{\text {th }}$ ) and mean curve in Fig. 5 result from connecting the corresponding percentile and mean values for individual normalized releases. Thus, these curves provide a compact summary for distributions of the form shown in Fig. 6. A CDF is used to represent the uncertainty in exceedance probabilities so that the distributions in Fig. 6 will have the same orientation as the percentile curves in Fig. 5 . 


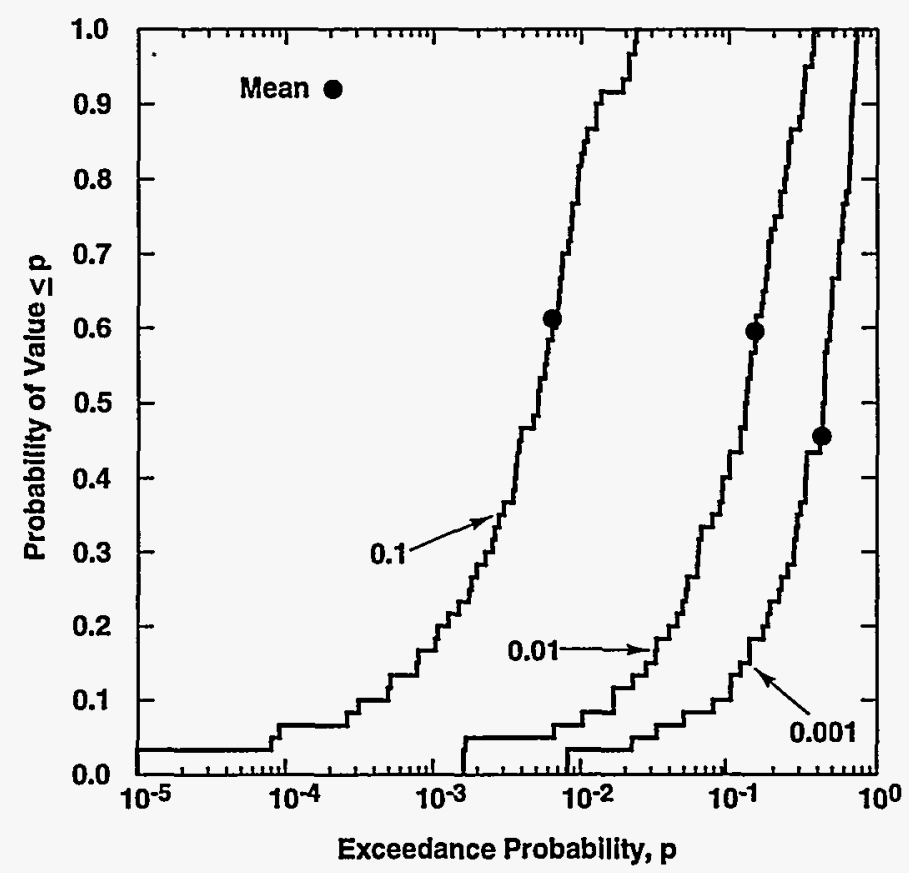

TRI-6342-4342-0

Fig. 6. Estimated CDFs for exceedance probabilities associated with normalized releases to the accessible environment of $R=0.001,0.01$ and 0.1 in Fig. 4 .

The percentile values on which the percentile curves in Fig. 5 are based are conditional on individual normalized release (i.e., $R$ ) values. Thus, these curves characterize the uncertainty in the probability that specific $R$ values will be exceeded rather than the uncertainty in the location of entire CCDFs. For example, it is inappropriate to conclude that there is a probability of 0.9 that a CCDF produced for a randomly selected element of $\mathcal{S}_{s u}$ will fall below the 90th percentile curve. The probability that a CCDF will fall below a specified boundary line (e.g., the boundary line defined in 40 CFR 191.13(a) and illustrated in Fig. 4) can be estimated by generating a sample from $\mathcal{S}_{s u}$ as indicated in Eq. (17) and then dividing the number of CCDFs below the boundary line by the sample size. In contrast as shown by the development leading to Eq. (19), connecting the mean exceedance probabilities for individual $R$ values produces the unconditional CCDF discussed in Sect. 3.1.

\subsection{CCDF Conditional on Element of $\delta_{s t}$}

The construction of a CCDF conditional on the occurrence of a specific element of $S_{s t}$ is now considered. This case is similar to the case considered in Sect. 3.2 for a CCDF conditional on the occurrence of a specific element of $\mathcal{S}_{s u}$. It is useful to first consider the more general case of a CCDF conditional on the occurrence of an arbitrary subset $\mathcal{E}_{s t}$ of $\mathcal{S}_{s t}$. The corresponding conditional CCDF for normalized release to the accessible environment has the form shown in Eq. (5), where the probability space under consideration is the product space associated with $\mathcal{S}_{s t} \times$ $\mathcal{S}_{s u}$. As a result, the CCDF is actually conditional on the occurrence of $\mathcal{E}_{s t} \times \mathcal{S}_{s u}$. Specifically, 


$$
\begin{aligned}
C C D F\left(R \mid \mathcal{E}_{s t} \times \mathcal{S}_{s u}\right) & =\int_{\mathcal{E}_{s t} \times S_{s u}} \delta_{R}[f(\mathbf{x})] d(\mathbf{x}) d V / \int_{\mathcal{E}_{s t} \times \mathcal{S}_{s u}} d(\mathbf{x}) d V, \quad \mathbf{x}=\left[\mathbf{x}_{s t}, \mathbf{x}_{s u}\right] \\
& =\int_{\mathcal{E}_{s t}} \int_{S_{s u}} \delta_{R}\left[f\left(\mathbf{x}_{s t}, \mathbf{x}_{s u}\right)\right] d_{s t}\left(\mathbf{x}_{s t} \mid \mathbf{x}_{s u}\right) d_{s u}\left(\mathbf{x}_{s u}\right) d V_{s u} d V_{s t} \\
& / \int_{\mathcal{E}_{s t}} \int_{S_{s u}} d_{s t}\left(\mathbf{x}_{s t} \mid \mathbf{x}_{s u}\right) d_{s u}\left(\mathbf{x}_{s u}\right) d V_{s u} d V_{s t}
\end{aligned}
$$

where $C C D F\left(R \mid \mathcal{E}_{s t} \times S_{s u}\right)$ is the probability that a normalized release of size $R$ will be exceeded conditional on the occurrence of $\varepsilon_{s t} \times S_{s u}$.

To obtain a CCDF conditional on the occurrence of an element $\tilde{\mathbf{x}}_{s t}$ of $S_{s t}$ it is necessary to consider the limit of the expression in Eq. (27) as the volumes of sets $\mathcal{E}_{s t}$ that contain $\tilde{\mathbf{x}}_{s t}$ go to zero (i.e., as $V\left(\varepsilon_{s t}\right) \rightarrow 0$ ). Given the ratio in Eq. (27), this limit does not have a simple form due to the dependence of $f\left(\mathbf{x}_{s t}, \mathbf{x}_{s u}\right)$ and $d_{s t}\left(\mathbf{x}_{s t} \mid \mathbf{x}_{s u}\right)$ on $\mathbf{x}_{s u}$. However, considerable simplification is possible provided there is no' relationship between the variables in $\mathbf{x}_{s u}$ that affect $f$ and the variables in $\mathbf{x}_{s u}$ that affect $d_{s t}$. As discussed in the next paragraph, this is the case in recent PAs for the WIPP.

In recent PAs for the WIPP, the probability space $\left(\mathcal{S}_{s u}, \delta_{s u}, p_{s u}\right)$ for subjective uncertainty is itself a product space obtained by combining a probability space $\left(\mathcal{S}_{s u, d}, \delta_{s u, d}, p_{s u, d}\right)$, which characterizes the uncertainty in variables used in the definition of the functions $p_{s t}$ and $d_{s t}$, and a probability space $\left(\mathcal{S}_{s u, f}, \delta_{s u, f}, p_{s u, f}\right)$, which characterizes the uncertainty in variables used in the definition of the function $f$. The elements $\mathbf{x}_{s u, d}$ of $\mathcal{S}_{s u, d}$ are of the form

$$
\mathbf{x}_{s u, d}=[B P A R E A F R, L A M B D A],
$$

where BPAREAFR and LAMBDA are defined in Table 1. Thus, $S_{s u, d}$ is a subset of $R^{2}$. The distributions indicated in Table 1 provide the information needed to complete the definition of $\left(\mathcal{S}_{s u, d}, \delta_{s u, d}, p_{s u, d}\right)$. Similarly, the elements $\mathbf{x}_{s u, f}$ of $\mathcal{S}_{s u, f}$ are vectors containing the remaining 43 variables indicated in Table 1 (i.e., $\mathcal{S}_{s u, f}$ is a subset of $R^{43}$ ) and the indicated distributions in Table 1 provide the information needed to complete the definition of $\left(\mathcal{S}_{s u, f}, \delta_{s u, f}\right.$, $\left.p_{s u, f}\right)$. As $S_{s u}=S_{s u, d} \times S_{s u, f}$, each element $\mathbf{x}_{s u}$ of $S_{s u}$ has the form

$$
\mathbf{x}_{s u}=\left[\mathbf{x}_{s u, d}, \mathbf{x}_{s u, f}\right]
$$

and is thus a vector from $R^{45}$ as previously noted. Further, the functions $f$ and $d_{s t}$ in Eq. (27) are actually of the form $f\left(\mathbf{x}_{s t}, \mathbf{x}_{s u, f}\right)$ and $d_{s t}\left(\mathbf{x}_{s t} \mid \mathbf{x}_{s u, d}\right)$ rather than $f\left(\mathbf{x}_{s t}, \mathbf{x}_{s u}\right)$ and $d_{s t}\left(\mathbf{x}_{s t} \mid \mathbf{x}_{s u}\right)$. Finally, if $\varepsilon_{s u, d} \in \&_{s u, d}, \varepsilon_{s u f} \in \&_{s u, f}$ and $\varepsilon_{s u}$ $=\varepsilon_{s u, d} \times \varepsilon_{s u, f}$, then 


$$
\begin{aligned}
p_{s u}\left(\mathcal{E}_{s u}\right) & =\int_{\mathcal{E}_{s u}} d_{s u}\left(\mathbf{x}_{s u}\right) d V_{s u} \\
& =\int_{\mathcal{E}_{s u, d}} \int_{\mathcal{E}_{s u, f}} d_{s u, d}\left(\mathbf{x}_{s u, d}\right) d_{s u, f}\left(\mathbf{x}_{s u, f}\right) d V_{s u, f} d V_{s u, d},
\end{aligned}
$$

where $d_{s u, d}$ and $d_{s u, f}$ are the density functions associated with the probability spaces $\left(\mathcal{S}_{s u, d}, \delta_{s u, d}, p_{s u, d}\right)$ and $\left(\mathcal{S}_{s u, f}\right.$ $\left.\delta_{s u, f}, p_{s u, f}\right)$, respectively, and the indicated decomposition in Eq. (30) follows from the assumed independence of the two preceding spaces.

Due to the considerations indicated in the preceding paragraph, the relationship in Eq. (27) is actually of the form

$$
\begin{aligned}
\operatorname{CCDF}\left(R \mid \mathcal{E}_{s t} \times S_{s u}\right) \\
=\int_{\mathcal{E}_{s t}} \int_{S_{s u, d}} \int_{\mathcal{S}_{s u, f}} \delta_{R}\left[f\left(\mathbf{x}_{s t}, \mathbf{x}_{s u, f}\right)\right] d_{s u, f}\left(\mathbf{x}_{s u, f}\right) d_{s u, d}\left(\mathbf{x}_{s u, d}\right) d_{s t}\left(\mathbf{x}_{s t} \mid \mathbf{x}_{s u, d}\right) d V_{s u, f} d V_{s u, d} d V_{s t} \\
\quad / \int_{\mathcal{E}_{s t}} \int_{\mathcal{S}_{s u, d}} \int_{\mathcal{S}_{s u, f}} d_{s u, f}\left(\mathbf{x}_{s u, f}\right) d_{s u, d}\left(\mathbf{x}_{s u, d}\right) d_{s t}\left(\mathbf{x}_{s t} \mid \mathbf{x}_{s u, d}\right) d V_{s u, f} d V_{s u, d} d V_{s t} \\
=\int_{\varepsilon_{s t}} \int_{\mathcal{S}_{s u, d}} \int_{\mathcal{S}_{s u, f}} \delta_{R}\left[f\left(\mathbf{x}_{s t}, \mathbf{x}_{s u, f}\right)\right] d_{s u, f}\left(\mathbf{x}_{s u, f}\right) d_{s u, d}\left(\mathbf{x}_{s u, d}\right) d_{s t}\left(\mathbf{x}_{s t} \mid \mathbf{x}_{s u, d}\right) d V_{s u, f} d V_{s u, d} d V_{s t} \\
\quad / \int_{\mathcal{E}_{s t}} \int_{\mathcal{S}_{s u, d}} d_{s u, d}\left(\mathbf{x}_{s u, d}\right) d_{s t}\left(\mathbf{x}_{s t} \mid \mathbf{x}_{s u, d}\right) d V_{s u, d} d V_{s t}
\end{aligned}
$$

in recent PAs for the WIPP.

The expression in Eq. (31) can now be used to obtain the CCDF for normalized release to the accessible environment conditional on the occurrence of an element $\tilde{\mathbf{x}}_{s t}$ of $\mathcal{S}_{s t}$. Specifically, with the assumption that $\tilde{\mathbf{x}}_{s t} \in$ $\varepsilon_{s t}$

$$
\begin{gathered}
C C D F\left(R \mid\left\{\tilde{\mathbf{x}}_{s t}\right\} \times S_{s u}\right)=\operatorname{limit}_{V\left(\varepsilon_{s t}\right) \rightarrow 0} \operatorname{CCDF}\left(R \mid \varepsilon_{s t} \times \delta_{s u}\right) \\
=\operatorname{limit}_{V\left(\varepsilon_{s t}\right) \rightarrow 0}\left\{\left[\int_{\mathcal{S}_{s u, d}} \int_{\delta_{s u, f}} \delta_{R}\left[f\left(\overline{\mathbf{x}}_{s t}, \mathbf{x}_{s u, f}\right)\right] d_{s u, f}\left(\mathbf{x}_{s u, f}\right) d_{s u, d}\left(\mathbf{x}_{s u, d}\right) d_{s t}\left(\overline{\mathbf{x}}_{s t} \mid \mathbf{x}_{s u, d}\right) d V_{s u, f} d V_{s u, d}\right] V\left(\varepsilon_{s t}\right)\right. \\
\left./\left[\int_{\delta_{s u, d}} d_{s u, d}\left(\mathbf{x}_{s u, d}\right) d_{s t}\left(\hat{\mathbf{x}}_{s t} \mid \mathbf{x}_{s u, d}\right) d V_{s u, d}\right] V\left(\varepsilon_{s t}\right)\right\}
\end{gathered}
$$

[from Eq. (31) by mean value theorem with $\overline{\mathbf{x}}_{s t}, \hat{\mathbf{x}}_{s t} \in \mathcal{E}_{s t}$ ]

18 


$$
\begin{aligned}
& =\operatorname{limit}_{V\left(\varepsilon_{s t}\right) \rightarrow 0}\left\{\int_{S_{s u, f}} \delta_{R}\left[f\left(\overline{\mathbf{x}}_{s t}, \mathbf{x}_{s u, f}\right)\right] d_{s u, f}\left(\mathbf{x}_{s u, f}\right) d V_{s u, f}\right\} \\
& \bullet\left\{\frac{\int_{S_{s u, d}} d_{s u, d}\left(\mathbf{x}_{s u, d}\right) d_{s t}\left(\overline{\mathbf{x}}_{s t} \mid \mathbf{x}_{s u, d}\right) d V_{s u, d}}{\int_{S_{s u, d}} d_{s u, d}\left(\mathbf{x}_{s u, d}\right) d_{s t}\left(\hat{\mathbf{x}}_{s t} \mid \mathbf{x}_{s u, d}\right) d V_{s u, d}}\right\} \\
& =\int_{S_{s u, f}} \delta_{R}\left[f\left(\tilde{\mathbf{x}}_{s t}, \mathbf{x}_{s u, f}\right)\right] d_{s u, f}\left(\mathbf{x}_{s u, f}\right) d V_{s u, f},
\end{aligned}
$$

provided the functions involved are "reasonably" behaved. The representation for $C C D F\left(R 1\left\{\tilde{\mathbf{x}}_{s t}\right\} \times S_{s u}\right)$ in Eq. (32) gives the probability that a normalized release of size $R$ will be exceeded conditional on the occurrence of the element $\tilde{\mathbf{x}}_{s t}$ of $S_{s t}$

As is the case for all integrals discussed in this presentation, the WIPP PA does not evaluate the integral in Eq. (32) directly. Rather, an approximation procedure is used. Specifically,

$$
C C D F\left(R \mid\left\{\mathbf{x}_{s t}\right\} \times S_{s u}\right) \doteq \sum_{k=1}^{n L H S} \delta_{R}\left[f\left(\mathbf{x}_{s t}, \mathbf{x}_{s u, f, k}\right)\right] / n L H S,
$$

where, in consistency with the notation used in Eq. (32), the elements of the Latin hypercube sample indicated in Eq. (17) are assumed to be of the form

$$
\mathbf{x}_{s u, k}=\left[\mathbf{x}_{s u, d, k}, \mathbf{x}_{s u, f, k}\right] .
$$

The 1991 WIPP PA evaluated CCDFs of the form defined in Eq. (33) for 10 elements of $S_{s t}$ : single drilling intrusions at 1,000,3,000,5,000, 7,000 and 9,000, yr and E1E2-type drilling intrusions at 1,000, 3,000, 5,000, 7,000 and 9,000 yr, where an E1E2-type intrusion involves two or more boreholes penetrating the same waste panel, with at least one intrusion penetrating a pressurized brine pocket and at least one intrusion not penetrating a pressurized brine pocket. The resultant CCDFs for groundwater transport to the accessible environment are shown in Fig. 7. As illustrated in Fig. 8, box plots are often used in the WIPP PA to summarize distributions of the form appearing in Fig. 7 due to their greater compactness and legibility.

If $\mathbf{x}_{s u}$ does not have the decomposition in Eq. (29), the outcome of evaluating the limit in Eq. (32) is

$$
\begin{aligned}
C C D F & \left(R \mid\left\{\tilde{\mathbf{x}}_{s t}\right\} \times S_{s u}\right) \\
& =\left[\int_{S_{s u}} \delta_{R}\left[f\left(\tilde{\mathbf{x}}_{s t}, \mathbf{x}_{s u}\right)\right] d_{s t}\left(\tilde{\mathbf{x}}_{s t} \mid \mathbf{x}_{s u}\right) d_{s u}\left(\mathbf{x}_{s u}\right) d V_{s u}\right] /\left[\int_{S_{s u}} d_{s t}\left(\tilde{\mathbf{x}}_{s t} \mid \mathbf{x}_{s u}\right) d_{s u}\left(\mathbf{x}_{s u}\right) d V_{s u}\right] \\
& =\int_{S_{s u}} \delta_{R}\left[f\left(\tilde{\mathbf{x}}_{s t}, \mathbf{x}_{s u}\right)\right] d_{s u}\left(\mathbf{x}_{s u} \mid \tilde{\mathbf{x}}_{s t}\right) d V_{s u},
\end{aligned}
$$




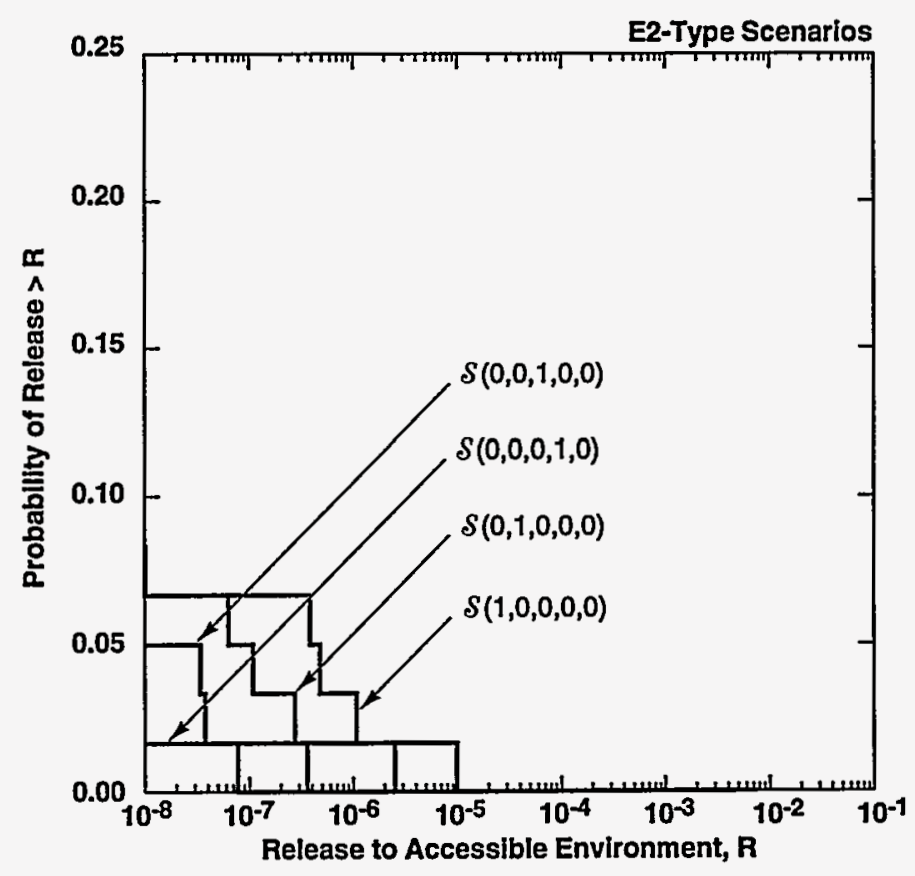

TRI-6342-4344-0

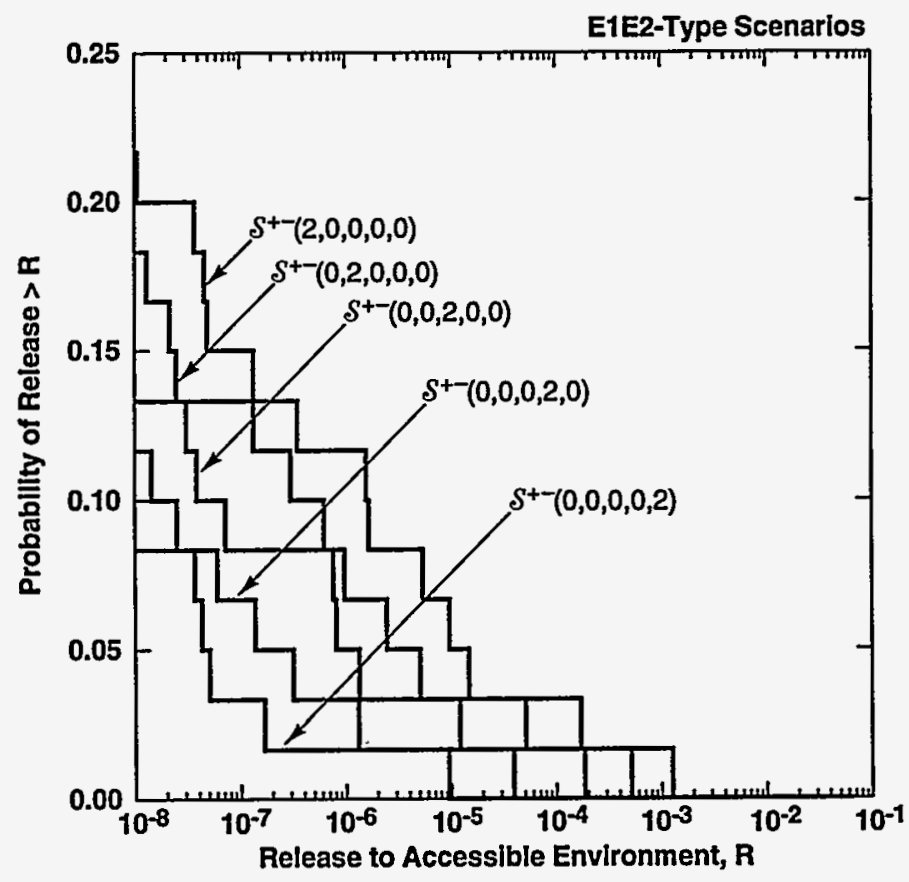

TRI-6342-4345-0

Fig. 7. Complementary cumulative distribution functions for normalized release to the accessible environment due to groundwater transport conditional on the occurrence of individual elements of $\mathcal{S}_{s t}$. The upper plot frame contains CCDFs for single intrusions at $1000,3000,5000$ and 7000 yrs (i.e., for scenarios $S(1,0,0,0,0)$, $\mathcal{S}(0,1,0,0,0), \mathcal{S}(0,0,1,0,0), \mathcal{S}(0,0,0,1,0)$ in the notation used in the 1991 WIPP PA); a single intrusion at 9000 yr (i.e., scenario $S(0,0,0,0,1))$ resulted in no release. The lower plot frame contains CCDFs for E1E2type drilling intrusions at $1000,3000,5000,7000$ and 9000 yrs (i.e., for scenarios $\mathcal{S}^{4-}(2,0,0,0,0), \ldots$, $\left.\mathcal{S}^{4-}(0,0,0,0,2)\right)$. 

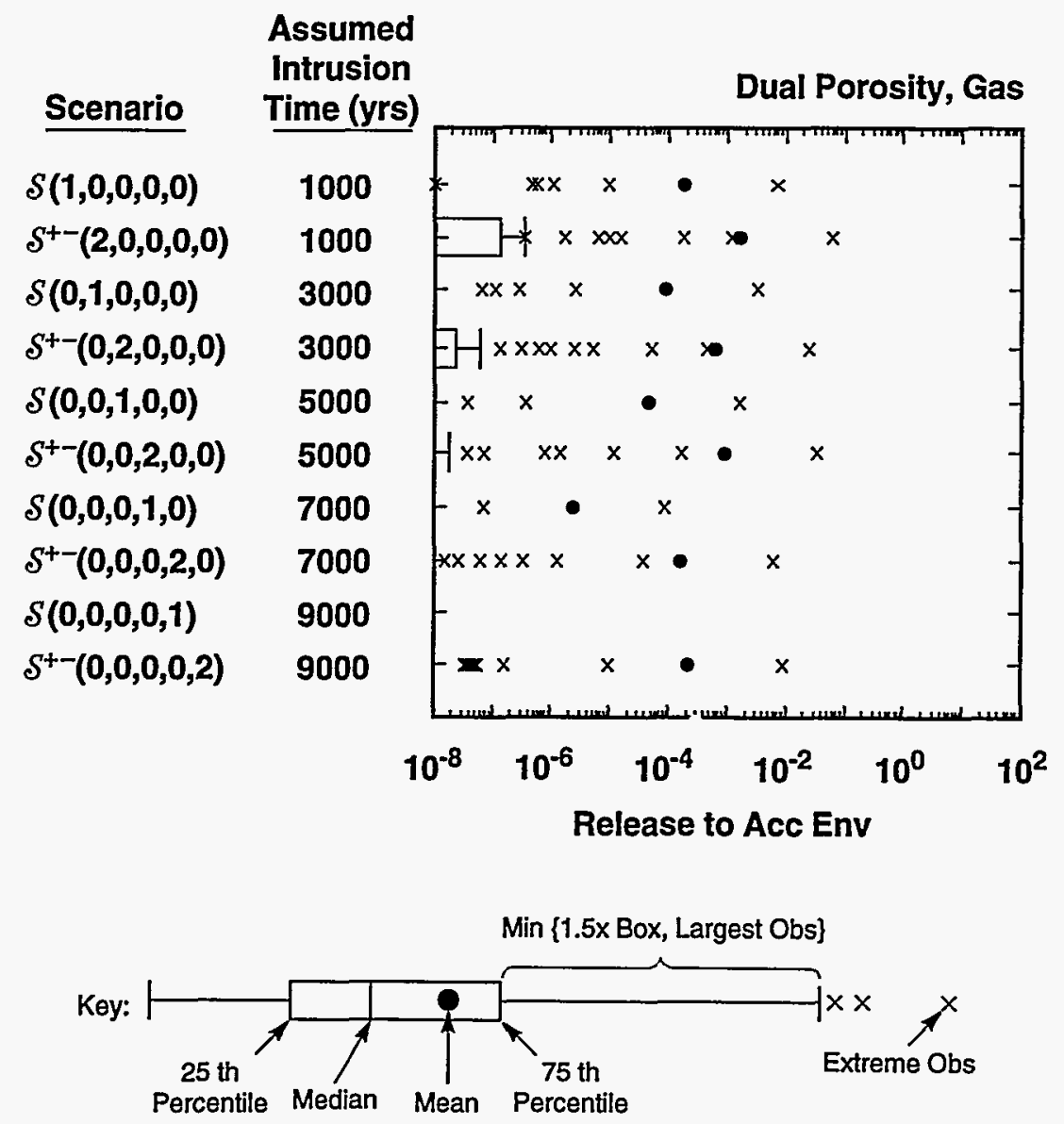

TRI-6342-2584-0

Fig. 8. Alternative summary of CCDFs in Fig. 7 with box plots (Ref. 24, Fig. 4.4-1; Ref. 49, Fig. 10). 
where $d_{s u}\left(\mathbf{x}_{s u} \mid \tilde{\mathbf{x}}_{s t}\right)$ is the density function for $\mathbf{x}_{s u}$ conditional on the occurrence of $\tilde{\mathbf{x}}_{s t}$ (Table 2). If a sample from $\mathcal{S}_{s u}$ of the form indicated in Eq. (17) is used, then the CCDF in Eq. (35) can be approximated by

$$
C C D F\left(R \mathbf{R}\left\{\tilde{\mathbf{x}}_{s t}\right\} \times \delta_{s u}\right) \doteq\left[\sum_{k=1}^{n L H S} \delta_{R}\left[f\left(\tilde{\mathbf{x}}_{s t}, \mathbf{x}_{s u, k}\right)\right] d_{s t}\left(\tilde{\mathbf{x}}_{s t} \mid \mathbf{x}_{s u, k}\right)\right] /\left[\sum_{k=1}^{n L H S} d_{s t}\left(\tilde{\mathbf{x}}_{s t} \mid \mathbf{x}_{s u, k}\right)\right],
$$

which is equivalent to use of the reweighting procedure proposed by Iman and Conover. ${ }^{54}$

\subsection{Alternate Construction of Unconditional CCDF on Product Space $\delta_{s t} \times \delta_{s u}$}

The unconditional quantity $C C D F(R)$ was obtained in Eq. (16) by integrating over the probability space associated with $S=S_{s t} \times S_{s u}$. As discussed in Sect. 3.2, $C C D F(R)$ is the mean of CCDFs conditional on individual elements of $\cdot S_{s u}$, with this mean being calculated with respect to $\left(\mathcal{S}_{s u}, \delta_{s u}, p_{s u}\right)$. Eqs. (18) and (24) show that an approximation to $C C D F(R)$ can be constructed by first approximating CCDFs conditional on elements of $\mathcal{S}_{s u}$ obtained by random or Latin hypercube sampling and then vertically averaging these CCDFs.

An alternate approximation procedure for $C C D F(R)$ is to calculate CCDFs conditional on elements of $S_{s t}$ as discussed in Sect. 3.4 and then vertically average these CCDFs over $\left(\mathcal{S}_{s t}, \delta_{s t}, p_{s t}\right)$. Formally,

$$
\begin{aligned}
C C D F(R) & =\int_{S_{s t}} C C D F\left(R \mid\left\{\mathbf{x}_{s t}\right\} \times S_{s u}\right) d_{s t}\left(\mathbf{x}_{s t}\right) d V_{s t}\left[\text { see Table } 2 \text { for definition of } d_{s t}\left(\mathbf{x}_{s t}\right)\right] \\
& =\int_{S_{s t}} \int_{S_{s u}} \delta_{R}\left[f\left(\mathbf{x}_{s t}, \mathbf{x}_{s u}\right)\right] d_{s t}\left(\mathbf{x}_{s t} \mid \mathbf{x}_{s u}\right) d_{s u}\left(\mathbf{x}_{s u}\right) d V_{s u} d V_{s t} \text { [from Eq. (35)] } \\
& =\int_{S_{s u}} \int_{S_{s t}} \delta_{R}\left[f\left(\mathbf{x}_{s t}, \mathbf{x}_{s u}\right)\right] d_{s t}\left(\mathbf{x}_{s t} \mid \mathbf{x}_{s u}\right) d_{s u}\left(\mathbf{x}_{s u}\right) d V_{s t} d V_{s u},
\end{aligned}
$$

which is the same outcome as in Eq. (16).

An approximation to $C C D F(R)$ is obtained by subdividing $S_{s t}$ into a sequence $\mathcal{S}_{s t, i}, i=1,2, \ldots, n S$, of disjoint subsets. Specifically,

$$
\begin{aligned}
C C D F(R) & =\sum_{i=1}^{n S} \int_{S_{s t, i}} C C D F\left(R \mid\left\{\mathbf{x}_{s t}\right\} \times \delta_{s u}\right) d_{s t}\left(\mathbf{x}_{s t}\right) d V_{s t}\left[\delta_{s t}=\bigcup_{i} \delta_{s t, i}, \delta_{s t, i} \cap \delta_{s t, j}=\phi \text { for } i \neq j\right] \\
& =\sum_{i=1}^{n S}\left\{C C D F\left(R \mid\left\{\mathbf{x}_{s t, i}\right\} \times \delta_{s u}\right)\right\}\left\{\int_{S_{s t, i}} d_{s t}\left(\mathbf{x}_{s t}\right) d V_{s t}\right\}
\end{aligned}
$$

[by generalized mean value of theorem with $\mathbf{x}_{s t, i} \in \mathcal{S}_{s t, i}$ ] 


$$
\begin{gathered}
=\sum_{i=1}^{n S}\left\{C C D F\left(R \mid\left\{\mathbf{x}_{s t, i}\right\} \times S_{s u}\right)\right\}\left\{\int_{S_{s u}}\left[\int_{S_{s t, i}} d_{s t}\left(\mathbf{x}_{s t} \mid \mathbf{x}_{s u}\right) d V_{s t}\right] d_{s u}\left(\mathbf{x}_{s u}\right) d V_{s u}\right\} \\
{\left[\text { from definition of } d_{s t}\left(\mathbf{x}_{s t}\right)\right. \text { in Table 2] }}
\end{gathered}
$$

where in the final equality

$$
p\left(S_{s t, i} \mid \mathbf{x}_{s u}\right)=\int_{S_{s t, i}} d_{s t}\left(\mathbf{x}_{s t} \mid \mathbf{x}_{s u}\right) d V_{s t}
$$

is the probability of $S_{s t, i}$ given $\mathbf{x}_{s u}$ and

$$
p\left(S_{s t, i}\right)=\int_{S_{s u}} p\left(S_{s t, i} \mid \mathbf{x}_{s u}\right) d_{s u}\left(\mathbf{x}_{s u}\right) d V_{s u}
$$

is the expected value of $p\left(S_{s t, i} \mid \mathbf{x}_{s u}\right)$ over $\left(S_{s u}, \delta_{s u}, p_{s u}\right)$.

If a sample from $S_{s u}$ of the form indicated in Eq. (17) is used, then the results in Eqs. (36) and (38) can be combined to obtain the following approximation to $C C D F(R)$ :

$$
\begin{aligned}
C C D F(R) \doteq \sum_{i=1}^{n S}\{[ & {\left.\left[\sum_{k=1}^{n L H S} \delta_{R}\left[f\left(\mathbf{x}_{s t, i}, \mathbf{x}_{s u, k}\right)\right] d_{s t}\left(\mathbf{x}_{s t, i} \mid \mathbf{x}_{s u, k}\right)\right],\left[\sum_{k=1}^{n L H S} d_{s t}\left(\mathbf{x}_{s t, i} \mid \mathbf{x}_{s u, k}\right)\right]\right\}_{1} } \\
& \cdot\left\{\sum_{k=1}^{n L H S}\left[\int_{S_{s t, i}} d_{s t}\left(\mathbf{x}_{s t} \mid \mathbf{x}_{s u, k}\right) d V_{s t}\right] / n L H S\right\}_{2},
\end{aligned}
$$

where $\{\sim\}_{1}$ is an approximation to a CCDF over subjective uncertainty conditional on the occurrence of an element $\mathbf{x}_{s t, i}$ of $S_{s t, i}$ and $\{\sim\}_{2}$ is an approximation to the expected value over subjective uncertainty for the probability of $S_{s t, i}$. If $\mathbf{x}_{s u}$ has the decomposition indicated in Eq. (29) and a sample of the form in Eq. (34) is used, then the results in Eqs. (33) and (38) can be combined to obtain

$$
C C D F(R) \doteq \sum_{i=1}^{n S}\left\{\sum_{k=1}^{n L H S} \delta_{R}\left[f\left(\mathbf{x}_{s t, i}, \mathbf{x}_{s u, f, k}\right)\right] / n L H S\right\}_{1}\left\{\sum_{k=1}^{n L H S}\left[\int_{S_{s t, i}} d_{s t}\left(\mathbf{x}_{s t} \mid \mathbf{x}_{s u, k}\right) d V_{s t}\right] / n L H S\right\}_{2},
$$

where $\{\sim\}_{1}$ and $\{\sim\}_{2}$ have the same interpretation as in Eq. (41).

The approximations to $C C D F(R)$ in Eqs. (41) and (42) both involve a construction procedure of the form indicated in Fig. 9, with CCDFs conditional on the occurrence of individual elements of $\mathcal{S}_{s t}$ being constructed and then vertically averaged to obtain an approximation to $C C D F(R)$. The first term (i.e., $\left.\{\sim\}_{1}\right)$ in Eqs. (41) and (42) is an approximation to the conditional CCDFs (i.e., to $C C D F\left(R \mid\left\{\mathbf{x}_{s t, i}\right\} \times \mathcal{S}_{s u}\right)$ in Fig. 9. The second term (i.e., $\left.\{\sim\}_{2}\right)$ in Eqs. (41) and (42) is an approximation to the probability (i.e., to $p\left(\mathcal{S}_{s t, i}\right)$ ) of the subsets $\mathcal{S}_{s t, i}$ of $\mathcal{S}_{s t}$ on which the 


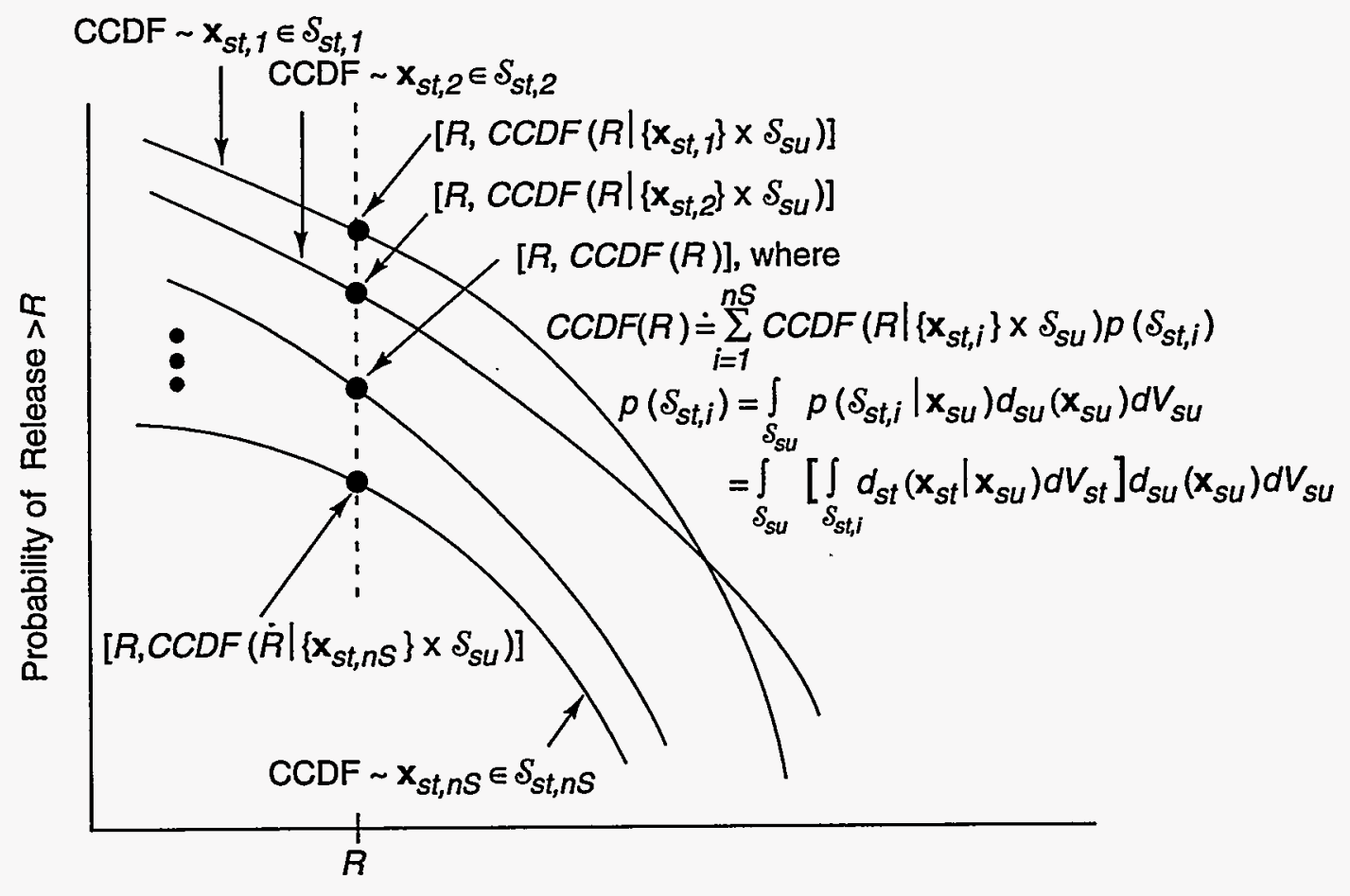

Release to Accessible Environment, $R$

TRI-6342-4393-0

Fig. 9. Construction of Unconditional CCDF on $\mathcal{S}_{s t} \times \mathcal{S}_{s u}$ (i.e., $C C D F(R)$ ) by Vertically Averaging CCDFs Conditional on the Occurrence of Elements of $S_{s t}$.

construction of $C C D F(R)$ is based. The summation in Eqs. (41) and (42) produces an approximation to the CCDF labeled $C C D F(R)$ in Fig. 9.

Although Eqs. (41) and (42) approximate $p\left(\mathcal{S}_{s t, i}\right)$ in the same manner, the approximations to $C C D F\left(R \mid\left\{\mathbf{x}_{s t, i}\right\} \times S_{s u}\right)$ are different. The independence of variables that affect $f\left(\mathbf{x}_{s t}, \mathbf{x}_{s u, f}\right)$ and $d_{s t}\left(\mathbf{x}_{s t} \mid \mathbf{x}_{s u, d}\right)$ in Eq. (42) allows the approximation to $C C D F\left(R \mid\left\{\mathbf{x}_{s t, i}\right\} \times \mathcal{S}_{s u}\right)$ to be constructed directly from the values of $f\left(\mathbf{x}_{s t, i}, \mathbf{x}_{s u f, k}\right)$ calculated for the sample elements $\mathbf{x}_{s u, f, k}, k=1,2, \ldots, n L H S$. In contrast, the corresponding lack of independence for Eq. (41) requires the inclusion of a weighting term in the approximation to $\operatorname{CCDF}\left(R \mid\left\{\mathbf{x}_{s t, i}\right\} \times S_{s u}\right)$.

The approximation procedure in Eq. (42) has often been proposed for estimating $C C D F(R)$, with there typically being no uncertainty in the probability for subsets $S_{s t, i}$ of $S_{s t}{ }^{55-59}$ However, there are two disadvantages to the use of Eq. (42). First, by directly constructing $C C D F(R)$ from CCDFs conditional on elements of $S_{s t}$, the uncertainty associated with $\left(\mathcal{S}_{s u}, \delta_{s u}, p_{s u}\right)$ that leads to multiple possible CCDFs for comparison with 40 CFR 191.13 is obscured. Second, when many subsets $S_{s t, i}$ of $S_{s t}$ are in use, this procedure can become computationally unwieldy. For example, $n S$ exceeded $10^{6}$ in the construction of some of the CCDFs in Fig. 4 (see Ref. 40, Table 2). In addition, the use of Eq. (41) when the variables associated with $\left(\delta_{s u}, \delta_{s u}, p_{s u}\right)$ that affect $f\left(\mathbf{x}_{s t}, \mathbf{x}_{s u}\right)$ and $d_{s t}\left(\mathbf{x}_{\mathrm{st}} \mid \mathbf{x}_{s u}\right)$ 
are not independent requires the inclusion of weights with the calculated results for individual sample elements. The requirements for these weights is the reason why the approximation in Eq. (20) of Ref. 15 will not, in general, produce the same CCDF as the approximations in Eqs. (19) and (41); however, it does produce the same CCDF as Eq. (42) when the variables that affect $f\left(\mathbf{x}_{s t}, \mathbf{x}_{s u}\right)$ and $d_{s t}\left(\mathbf{x}_{s t} \mid \mathbf{x}_{s u}\right)$ are independent. 
This page intentionally left blank. 


\section{Discussion}

As evidenced by the extensive discussion in Refs. 1-20, much interest exists in the treatment of uncertainty in PAs for complex systems. Indeed, the incorporation of uncertainty into the outcomes of an analysis is the essence of a PA for a complex system. However, appropriately drawing a distinction between the uncertainty that arises because the system can behave in many different ways (i.e., stochastic uncertainty) and the uncertainty that arises from a lack of knowledge on the part of the analysts conducting the PA (i.e., subjective uncertainty) remains an area of considerable confusion.

This presentation describes and illustrates a formal approach to representing the uncertainty in a PA for a complex system in which a probability space $\left(\mathcal{S}_{s t}, \delta_{s t}, p_{s t}\right)$ is used to characterize stochastic uncertainty, a probability space $\left(\delta_{s u}, \delta_{s u}, p_{s u}\right)$ is used to characterize subjective uncertainty, and the models used in the PA are functions (i.e., random variables) defined on the product space associated with $\left(\mathcal{S}_{s t}, \&_{s t}, p_{s t}\right)$ and $\left(\mathcal{S}_{s u}, \delta_{s u}, p_{s u}\right)$. Initially, this can sound very complicated. However, this structure produces a relatively simple conceptual description of a PA into which the many individual components of the PA can be placed and leads naturally to the actual calculations that are performed within a PA.

The development of the probability space $\left(\delta_{s t}, \delta_{s t}, p_{s t}\right)$ is central to all PAs. For example, the fault and event tree techniques that play an important role in many large analyses can be viewed as algorithms for developing, or at least approximating, $\left(S_{s t}, \delta_{s t}, p_{s t}\right)$. An inevitably-posed question in every large PA involves completeness; specifically "Did the PA consider everything that could occur in the system under study?". What this question is actually asking is whether or not the sample space $S_{s t}$ was appropriately defined. Another activity that arises in one form or another in all PAs is scenario development and involves the selection of subsets of $\mathcal{S}_{s t}$ for consideration in the PA. Typically, scenarios are elements of $b_{s t}$ for which probabilities are determined and consequence calculations are carried out. Thus, scenario development can be viewed as the determination of sets in $\mathscr{\delta}_{s t}$ for inclusion in the PA. Finally, $p_{s t}$ must be developed if probabilistic statements are to be made about occurrences in the system under study. An important point that should be recognized is that, although probabilities are determined for subsets of $S_{s t}$, consequence calculations are performed for individual elements of $\delta_{s t}$. Thus, an important consideration in scenario development is to obtain subsets of $\delta_{s t}$ that are reasonably homogeneous so that a calculation performed for an arbitrary element of $\mathcal{S}_{s t}$ in a scenario will produce results that are reasonably close to what would be obtained for any other element of $S_{s t}$ associated with the scenario.

A clear conceptual model for a PA is very important. At the same time, it is important to recognize how computational practice diverges from this conceptual model. For example, in most large analyses $\delta_{s t}, \&_{s t}$ and $p_{s t}$ are never fully developed. Rather, fault and event tree techniques or some other construction procedure are used to develop a collection of disjoint sets that spans $\mathcal{S}_{s t}$. The nature of $\mathcal{S}_{s t}$ is then inferred from these sets, and $p_{s t}$ is defined only for these sets. Thus, although a probability space $\left(\delta_{s t}, \delta_{s t}, p_{s t}\right)$ for stochastic uncertainty underlies the 
analysis, this space is never known completely. Rather, enough information about $\left(\delta_{s t}, \&_{s t}, p_{s t}\right)$ is developed to allow the analysis to be performed but a complete construction of $\left(\mathcal{S}_{s t}, \delta_{s t}, p_{s t}\right)$ is not carried out.

Much of what is done in a PA involves integrations performed with the probability spaces $\left(\delta_{s t}, \&_{s t}, p_{s t}\right)$ and $\left(\mathcal{S}_{s u}, \delta_{s u}, p_{s u}\right)$. Integration of suitably defined functions over $\left(\mathcal{S}_{s t}, \delta_{s t}, p_{s t}\right)$ leads to the CCDFs that are typically presented as the outcomes of PAs for complex systems. For most systems, integration procedures based on importance sampling or Monte Carlo techniques are used. In the example contained in this presentation, an integration procedure based on importance sampling was used to estimate the CCDF specified in the EPA's regulation 191.13(a) for the geologic disposal of radioactive waste. This CCDF could also have been estimated with Monte Carlo procedures. ${ }^{60}$ The fault tree and event tree techniques used in many large analyses to develop scenarios can also be viewed as algorithms to define importance sampling procedures for integration over $\left(S_{s t}, \&_{s t}, p_{s t}\right)$. Importance sampling procedures are often used because they provide a way to assure the inclusion of low probability but possibly high consequence subsets of $S_{s t}$ in the analysis. What are rather lightly referred to as "suitably defined functions" at the beginning of this paragraph are often sequences of complex computer programs. Thus, the closed form evaluation of integrals is typically not a possibility in PAs for complex systems.

The probability space $\left(\mathcal{S}_{s u}, \delta_{s u}, p_{s u}\right)$ enters a PA when it is desired to express the analysts' confidence in the outcomes of the study. Often, $\left(\mathcal{S}_{s u}, \delta_{s u}, p_{s u}\right)$ is developed at least in part through an expert review process in which distributions are developed to characterize the state of knowledge uncertainty in individual variables used in the analyses. Taken collectively, these distributions then define $\left(\mathcal{S}_{s u}, \mathscr{S}_{s u}, p_{s u}\right)$. In the example contained in this presentation, the uncertainty characterized by $\left(\delta_{s u}, \delta_{s u}, p_{s u}\right)$ leads to an assessment of the "reasonable expectation" called for in the EPA's regulation 191.13(b). As for $\left(S_{s t}, \delta_{s t}, p_{s t}\right)$, the implications of the uncertainty characterized by $\left(S_{s u}, \delta_{s u}, p_{s u}\right)$ must be determined by numerical integration procedures. Possibilities include the discrete probability method ${ }^{61}$ and Monte Carlo procedures based on simple random sampling or Latin hypercube sampling. The example contained in this presentation and also the NUREG-1150 probabilistic risk assessments ${ }^{13,62}$ used Latin hypercube sampling because of its efficient stratification properties.

The integration procedures indicated in the two preceding paragraphs can also be viewed as the outcome of experimental designs applied to $S_{s t}$ and $\delta_{s u}$. Thus, the subdivision of $S_{s t}$ into scenarios (i.e.., elements of $b_{s t}$ ) is an experimental design based on importance sampling. Similarly, the use of Monte Carlo procedures based on simple random sampling or Latin hypercube sampling can be viewed as generating random designs.

The Kaplan/Garrick ordered triple representation for risk $^{2}$ provides a useful way to view the structure of a PA that is consistent with the ideas discussed in this presentation. In the Kaplan/Garrick representation, risk is represented by a set $R$ of the form

$$
R=\left\{\left(\mathcal{S}_{i}, p S_{i}, c S_{i}\right), i=1, \ldots, n S\right\},
$$


where $S_{i}$ is a set of similar occurrences, $p S_{i}$ is the probability that an occurrence in the set $S_{i}$ will take place, $c S_{i}$ is a vector of consequence associated with $S_{i}, n S$ is the number of sets selected for consideration, the sets $S_{i}$ have no occurrences in common, and $\cup_{i} \mathcal{S}_{i}$ contains everything that could occur in the system under consideration. In the context of the probability space $\left(\mathcal{S}_{s t}, \mathscr{\delta}_{s t}, p_{s t}\right)$, the $S_{i}$ are elements of $\mathscr{S}_{s t}$, the sample space $S_{s t}$ is equal to $\cup_{i} \mathcal{S}_{i}$, and $p S_{i}$ is equal to $p_{s t}\left(S_{i}\right)$. Further, $\mathbf{c S}_{i}$ is obtained by evaluating a function $f$ for a suitably selected element of $\mathcal{S}_{i}$; another possibility is that $\mathbf{C S}_{i}$ is the expected value of $f$ on $S_{i}$ but this usage is less common. Thus, the Kaplan/Garrick ordered triple representation for risk is simply a way to develop the CCDFs for the probability space $\left(S_{s t}, \delta_{s t}, p_{s t}\right)$ and an associated function $f$ defined on $S_{s t}$.

Subjective uncertainty enters into the risk representation in Eq. (43) through the recognition that $R$ is actually a function of the form

$$
R(\mathbf{x})=\left\{\left[S_{i}(\mathbf{x}), p S_{i}(\mathbf{x}), c S_{i}(\mathbf{x})\right], i=1, \ldots, n S(\mathbf{x})\right\}
$$

where

$$
\mathbf{x}=\left[x_{1}, x_{2}, \ldots, x_{n V}\right]
$$

is a vector of imprecisely known inputs required in the analysis. Lack of knowledge about $\mathbf{X}$ is subjective uncertainty and is characterized by the probability space $\left(\delta_{s u}, \delta_{s u}, p_{s u}\right)$. In practice, $\left(\delta_{s u}, \delta_{s u}, p_{s u}\right)$ is defined by a sequence of distributions

$$
D_{1}, D_{2}, \ldots, D_{n V}
$$

for the individual elements $x_{j}$ of $\mathbf{X}$. The effect of this uncertainty is typically characterized by generating a random or Latin hypercube sample

$$
\mathbf{x}_{k}, k=1,2, \ldots, n K
$$

of size $n K$ according to the distributions in Eq. (46) and then evaluating

$$
\Re\left(\mathbf{x}_{k}\right)=\left\{\left[S_{i}\left(\mathbf{x}_{k}\right), p S_{i}\left(\mathbf{x}_{k}\right), \mathbf{c} \mathbf{S}_{i}\left(\mathbf{x}_{i}\right)\right], i=1, \ldots, n S\left(\mathbf{x}_{k}\right)\right\}
$$

for $k=1,2, \ldots, n K$. The preceding procedure leads to representations of uncertainty of the form shown in Figs. 4-7 and is equivalent to integrating over the probability space $\left(\delta_{s u}, \delta_{s u}, p_{s u}\right)$ as discussed in this presentation.

An often contentious point that arises in many PAs is whether or not it is meaningful to have a "probability of a probability." Such a probability arises quite naturally when product spaces are considered. As discussed in Sect. 3.3 and illustrated in Fig. 6, a probability can arise from one probability space (e.g., $\left(\mathcal{S}_{s t}, \delta_{s t}, p_{s t}\right)$ in this presentation) 
and a distribution for this probability can arise from another probability space (e.g., $\left(\delta_{s u}, \&_{s u}, p_{s u}\right)$ in this presentation).

A phrase often used in conjunction with PAs for complex systems is "uncertainty and sensitivity analysis." Uncertainty analysis involves determining the uncertainty in analysis outcomes that derives from uncertainty with respect to the correctness of the assumptions used in the analysis. In the terminology of this presentation, uncertainty analysis is an investigation of the effects of subjective uncertainty. Indeed, the primary purpose of this presentation is to provide a formal description of uncertainty analysis in which the dependent variable of interest is a CCDF that results from stochastic uncertainty. Sensitivity analysis involves determining the effects of the uncertainty in individual variables on various analysis outcomes of interest (e.g., the probability of exceeding a given consequence value). ${ }^{63}$ Although not emphasized in this presentation, sensitivity analysis typically involves determining the effects of individual variables associated with the probability space $\left(\mathcal{S}_{s u}, \mathscr{b}_{s u}, p_{s u}\right)$ on either a function $f$ evaluated at a specific point in $S_{s t}$ (e.g., see Ref. 49, Tables IX, X, XI) or an exceedance probability that results from integrating $f$ over $\left(S_{s t}, \delta_{s t}, p_{s t}\right)$ (e.g., see Ref. 49, Figs. 27, 28). The modifier "typically" is used in the preceding sentence because it is also possible, though less commonly done, to use sensitivity analysis techniques to investigate the effects of the variability associated with $\left(\mathcal{S}_{s t}, \delta_{s t}, p_{s t}\right)$ on predicted quantities of interest.

The division of uncertainty into stochastic uncertainty and subjective uncertainty greatly helps in the organization of a large analysis. At times it is argued that this distinction is artificial. However, when the actual computational implementation of an analysis must be confronted, the necessary distinctions are usually apparent. When these distinctions are not immediately apparent, evaluating them forces the analysts to come to grips with the nature of the system that they are studying and the analysis that they are conducting. Even if there is doubt as to how an uncertainty should be classified, the use of a formal structure to describe the analysis should leave no doubt as to how this uncertainty was actually treated. There is nothing wrong with differing views on how an analysis should be conducted and uncertainty treated within the analysis. What is unacceptable is to be unable to determine what was done after an analysis is completed.

This presentation has described a paradigm for the description and organization of a PA for a complex system. In this paradigm, a PA involves three basic components: a probability space $\left(S_{s t}, \delta_{s t}, p_{s t}\right)$ for stochastic uncertainty, a probability space $\left(S_{s u}, \delta_{s u}, p_{s u}\right)$ for subjective uncertainty, and a function defined on the product space associated with $\left(\mathcal{S}_{s t}, \mathcal{S}_{s t}, p_{s t}\right)$ and $\left(\mathcal{S}_{s u}, \mathcal{\&}_{s u}, p_{s u}\right)$. All of the basic results used in expressing the outcomes of a PA can be described in terms of these three components. The formalism associated with this paradigm is certainly not for presentation to all groups that may be involved in or interested in a given PA. However, there should be a core of individuals associated with any PA who have a clear conceptual understanding of the organization of the analysis. These individuals can then assure that the treatment of uncertainty and the modeling of physical processes is consistent with this organization and that analysis results are presented in a way that properly communicates what 
was done in the analysis. The structure described and illustrated in this presentation provides a basis for such an understanding. 
This page intentionally left blank. 


\section{References}

1. Lewis, H.W., R.J. Budnitz, H.J.C. Kouts, W.B. Loewenstein, W.D. Rowe, F. von Hippel, and F. Zachariasen. 1978. Risk Assessment Review Group Report to the U.S. Nuclear Regulatory Commission. NUREG/CR-0400. Washington, DC: U.S. Nuclear Regulatory Commission.

2. Kaplan, S., and B.J. Garrick. 1981. "On the Quantitative Definition of Risk," Risk Analysis. Vol. 1, no. 1, 11-27.

3. Vesely, W.E., and D.M. Rasmuson. 1984. "Uncertainties in Nuclear Probabilistic Risk Analyses," Risk Analysis. Vol. 4, no. 4, 313-322.

4. Paté-Cornell, M.E. 1986. "Probability and Uncertainty in Nuclear Safety Decisions," Nuclear Engineering and Design. Vol. 93, no. 2-3, 319-327.

5. Whipple, C.G. 1986. "Dealing with Uncertainty about Risk in Risk Management," in Hazards: Technology and Fairness. National Academy of Engineering. Washington, DC: National Academy Press. 44-59.

6. Silbergeld, E.K. 1987. "Five Types of Ambiguity: Scientific Uncertainty in Risk Assessment," Hazardous Waste and Hazardous Materials. Vol. 4, no. 2, 139-150.

7. Parry, G.W. 1988. "On the Meaning of Probability in Probabilistic Safety Assessment," Reliability Engineering and System Safety. Vol. 23, no. 4, 309-314.

8. Apostolakis, G.E. 1989. "Uncertainty in Probabilistic Risk Assessment," Nuclear Engineering and Design. Vol. 115, 173-179.

9. International Atomic Energy Agency. 1989. Evaluating the Reliability of Predictions Made Using Environmental Transfer Models. Safety Series Report No. 100. Vienna, Austria: International Atomic Energy Agency.

10. Apostolakis, G. 1990. "The Concept of Probability in Safety Assessments of Technological Systems," Science. Vol. 250, no. 4986, 1359-1364.

11. Finkel, A.M. 1990. Confronting Uncertainty in Risk Management: A Guide for Decision-Makers. Washington, DC: Center for Risk Management, Resources for the Future. 
12. McKone, T.E., and K.T. Bogen. 1991. "Predicting the Uncertainties in Risk Assessment," Environmental Science and Technology. Vol. 25, no. 10, 1674-1681.

13. Breeding, R.J., J.C. Helton, E.D. Gorham, and F.T. Harper. 1992. "Summary Description of the Methods Used in the Probabilistic Risk Assessments for NUREG-1150," Nuclear Engineering and Design. Vol. 135, no. 1, 1-27.

14. Anderson, E., P.F. Deisler, Jr., D. McCallum, C. St. Hilaire, H.L. Spitzer, H. Strauss, J.D. Wilson, and R. Zimmerman. 1993. "Key Issues in Carcinogen Risk Assessment Guidelines, Society for Risk Analysis," Risk Analysis. Vol. 13, no. 4, 379-382.

15. Helton, J.C. 1993. "Risk, Uncertainty in Risk, and the EPA Release Limits for Radioactive Waste Disposal," Nuclear Technology. Vol. 101, no. 1, 18-39.

16. Kaplan, S. 1993. "Formalisms for Handling Phenomenological Uncertainties: The Concepts of Probability, Frequency, Variability, and Probability of Frequency," Nuclear Technology. Vol. 102, no. 1, 137-142.

17. U.S. EPA (Environmental Protection Agency). 1993. An SAB Report: Multi-Media Risk Assessment for Radon, Review of Uncertainty Analysis of Risks Associated with Exposure to Radon. EPA-SAB-RAC-93014. Washington, DC: U.S. Environmental Protection Agency, Science Advisory Board.

18. Hoffman, F.O., and J.S. Hammonds. 1994. "Propagation of Uncertainty in Risk Assessments: The Need to Distinguish Between Uncertainty Due to Lack of Knowledge and Uncertainty Due to Variability," Risk Analysis. Vol. 14, 707-712.

19. National Research Council. 1994. Science and Judgment in Risk Assessment. Washington, DC: National Academy Press.

20. Helton, J.C. 1994. "Treatment of Uncertainty in Performance Assessments for Complex Systems," Risk Analysis. Vol. 14, no. 4, 483-511.

21. WIPP Performance Assessment Division. 1991. Preliminary Comparison with 40 CFR Part 191, Subpart B for the Waste Isolation Pilot Plant, December 1991. Volume 1: Methodology and Results. SAND910893/1. Albuquerque, NM: Sandia National Laboratories.

22. WIPP Perfornance Assessment Division. 1991. Preliminary Comparison with 40 CFR Part 191, Subpart $B$ for the Waste Isolation Pilot Plant, December 1991. Volume 2: Probability and Consequence Modeling. SAND91-0893/2. Albuquerque, NM: Sandia National Laboratories. 
23. WIPP Performance Assessment Division. 1991. Preliminary Comparison with 40 CFR Part 191, Subpart $B$ for the Waste Isolation Pilot Plant, December 1991. Volume 3: Reference Data. SAND91-0893/3. Albuquerque, NM: Sandia National Laboratories.

24. Helton, J.C., J.W. Garner, R.P. Rechard, D.K. Rudeen, and P.N. Swift. 1992. Preliminary Comparison with 40 CFR Part 191, Subpart B for the Waste Isolation Pilot Plant, December 1991. Volume 4: Uncertainty and Sensitivity Analysis Results. SAND91-0893/4. Albuquerque, NM: Sandia National Laboratories.

25. WIPP PA (Performance Assessment) Department. 1992. Preliminary Performance Assessment for the Waste Isolation Pilot Plant, December 1992-Volume 1: Third Comparison with 40 CFR 191, Subpart B. SAND92-0700/1. Albuquerque, NM: Sandia National Laboratories.

26. WIPP PA (Performance Assessment) Department. 1992. Preliminary Performance Assessment for the Waste Isolation Pilot Plant, December 1992-Volume 2: Technical Basis. SAND92-0700/2. Albuquerque, NM: Sandia National Laboratories.

27. Sandia WIPP Project. 1992. Preliminary Performance Assessment for the Waste Isolation Pilot Plant, December 1992-Volume 3: Model Parameters. SAND92-0700/3. Albuquerque, NM: Sandia National Laboratories.

28. WIPP PA (Performance Assessment) Department. 1993. Preliminary Performance Assessment for the Waste Isolation Pilot Plant, December 1992-Volume 4: Uncertainty and Sensitivity Analyses for 40 CFR 191, Subpart B. SAND92-0700/4. Albuquerque, NM: Sandia National Laboratories.

29. WIPP PA (Performance Assessment) Department. 1993. Preliminary Performance Assessment for the Waste Isolation Pilot Plant, December 1992-Volume 5: Uncertainty and Sensitivity Analyses of Gas and Brine Migration for Undisturbed Performance. SAND92-0700/5. Albuquerque, NM: Sandia National Laboratories.

30. Feller, W. 1971. An Introduction to Probability Theory and Its Applications. 2nd ed. New York, NY: John Wiley and Sons. Vol. II.

31. Ash, R.B. 1972. Real Analysis and Probability. New York, NY: Academic Press.

32. Breiman, L. 1992. Probability. Philadelphia, PA: Society for Industrial and Applied Mathematics. 
33. U.S. EPA (Environmental Protection Agency). 1985. "Environmental Standards for the Management and Disposal of Spent Nuclear Fuel, High-Level and Transuranic Radioactive Wastes; Final Rule, 40 CFR Part 191," Federal Register. Vol. 50, no. 182, 38066-38089.

34. U.S. EPA (Environmental Protection Agency). 1993. "40 CFR Part 191 Environmental Radiation Protection Standards for the Management and Disposal of Spent Nuclear Fuel, High-Level and Transuranic Radioactive Wastes; Final Rule." Federal Register. Vol. 58, no. 242, 66398-66416.

35. Farmer, F.R. 1967. "Reactor Safety and Siting: A Proposed Risk Criterion," Nuclear Safety. Vol. 8, no. 6, 539-548.

36. Cox, D.C., and P. Baybutt. 1982. "Limit Lines for Risk," Nuclear Technology. Vol. 57, no. 3, 320-330.

37. Munera, H.A., and G. Yadigaroglu. 1986. "On Farmer's Line, Probability Density Functions, and Overall Risk," Nuclear Technology. Vol. 74, no. 2, 229-232.

38. Helton, J.C., and R.J. Breeding. 1993. "Calculation of Reactor Accident Safety Goals," Reliability Engineering and System Safety. Vol. 39, no. 2, 129-158.

39. Helton, J.C. 1993. "Drilling Intrusion Probabilities for Use in Performance Assessment for Radioactive Waste Disposal," Reliability Engineering and System Safety. Vol. 40, no. 3, 259-275.

40. Helton, J.C., and H.J. Iuzzolino. 1993. "Construction of Complementary Cumulative Distribution Functions for Comparison with the EPA Release Limits for Radioactive Waste Disposal," Reliability Engineering and System Safety. Vol. 40, no. 3, 277-293.

41. Helton, J.C., D.R. Anderson, B.L. Baker, J.E. Bean, J.W. Berglund, W. Beyeler, J.W. Garner, H.J. Iuzzolino, M.G. Marietta, R.P. Rechard, P.J. Roache, D.K. Rudeen, J.D. Schreiber, P.N. Swift, M.S. Tierney, and P. Vaughn. 1995. . "Effect of Alternative Conceptual Models in a Preliminary Performance Assessment for the Waste Isolation Pilot Plant," Nuclear Engineering and Design. Vol. 154, no. 3, 251-344.

42. Berglund, J.W. 1992. Mechanisms Governing the Direct Removal of Wastes from the Waste Isolation Pilot Plant Repository Caused by Exploratory Drilling. SAND92-7295. Albuquerque, NM: Sandia National Laboratories.

43. Roache, P.J. 1993. "The SECO Suite of Codes for Site Performance Assessment," High Level Radioactive Waste Management, Proceedings of the Fourth Annual International Conference, Las Vegas, NV, April 26- 
30, 1993. La Grange Park, IL: American Nuclear Society, Inc.; New York, NY: American Society of Civil Engineers. Vol. 2, 1586-1594.

44. Huyakorn, P.S., H.O. White, Jr., and S. Panday. 1991. STAFF2D Solute Transport and Fracture Flow in 2-Dimensions. Herndon, VA: HydroGeoLogic, Inc. (Copy on file in the Sandia WIPP Central Files, Sandia National Laboratories, Albuquerque, NM.)

45. Mosleh, A., V.M. Bier, and G. Apostolakis. 1988. "A Critique of Current Practice for the Use of Expert Opinions in Probabilistic Risk Assessment," Reliability Engineering and System Safety. Vol. 20, no. 1, 63-85.

46. Hora, S.C., and R.L. Iman. 1989. "Expert Opinion in Risk Analysis: The NUREG-1150 Methodology," Nuclear Science and Engineering. Vol. 102, no. 4, 323-331.

47. Bonano, E.J., S.C. Hora, R.L. Kenney, and D. von Winterfeldt. 1990. Elicitation and Use of Expert Judgment in Performance Assessment for High-Level Radioactive Waste Repositories. NUREG/CR-5411, SAND89-1821. Albuquerque, NM: Sandia National Laboratories.

48. Ortiz, N.R., T.A. Wheeler, R.J. Breeding, S. Hora, M.A. Meyer, and R.L. Keeney. 1991. "Use of Expert Judgement in NUREG-1150," Nuclear Engineering and Design. Vol. 126, no. 3, 313-321.

49. Helton, J.C., J.W. Garner, M.G. Marietta, R.P. Rechard, D.K. Rudeen, and P.N. Swift. 1993. "Uncertainty and Sensitivity Analysis Results Obtained in a Preliminary Performance Assessment for the Waste Isolation Pilot Plant," Nuclear Science and Engineering. Vol. 114, no. 4, 286-331.

50. Oak Ridge National Laboratory. 1990. 1990 Integrated Data Base: U.S. Spent Fuel and Radioactive Waste Inventories, Projections, and Characteristics. DOE/RW-0006, Rev. 6. Oak Ridge, TN: Oak Ridge National Laboratory.

51. McKay, M.D., W.J. Conover, and R.J. Beckman. 1979. "A Comparison of Three Methods for Selecting Values of Input Variables in the Analysis of Output from a Computer Code," Technometrics. Vol. 21, no. 2, 239-245.

52. Iman, R.L., and M.J. Shortencarier. 1984. A FORTRAN 77 Program and User's Guide for the Generation of Latin Hypercube and Random Samples for Use with Computer Models. NUREG/CR-3624, SAND832365. Albuquerque, NM: Sandia National Laboratories.

53. Hammersley, J.M., and D.C. Handscomb. 1964. Monte Carlo Methods. London: Metheun; New York, NY: John Wiley \& Sons, Inc. 
54. Iman, R.L., and W.J. Conover. 1980. "Small Sample Sensitivity Analysis Techniques for Computer Models, With an Application to Risk Assessment," Communications in Statistics. Vol. A9, no. 17, 1749-1842. "Rejoinder to Comments," Ibid., 1863-1874.

55. Ortiz, N.R., and R.M. Cranwell. 1982. Risk Assessment Methodology for High Level Waste: Assessing Compliance with the EPA Draft Standard Including Uncertainties. SAND82-0596. Albuquerque, NM: Sandia National Laboratories.

56. Hunter, R.L., R.M. Cranwell, and M.S.Y. Chu. 1986. Assessing Compliance with the EPA High-Level Waste Standard: An Overview. NUREG/CR-4510, SAND86-0121. Albuquerque, NM: Sandia National Laboratories.

57. Cranwell, R.M., J.E. Campbell, J.C. Helton, R.L. Iman, D.E. Longsine, N.R. Ortiz, G.E. Runkle, and M.J. Shortencarier. 1987. Risk Methodology for Geologic Disposal of Radioactive Waste: Final Report. NUREG/CR-2452, SAND81-2573. Albuquerque, NM: Sandia National Laboratories.

58. Bonano, E.J., and K.K. Wahi. 1990. Use of Performance Assessment in Assessing Compliance with the Containment Requirements in 40 CFR Part 191. NUREG/CR-5521, SAND90-0127. Albuquerque, NM: Sandia National Laboratories.

59. Rechard, R.P. 1989, Review and Discussion of Code Linkage and Data Flow in Nuclear Waste Compliance Assessments. SAND87-2833. Albuquerque, NM: Sandia National Laboratories.

60. Helton, J.C., and A.W. Shiver. 1994. A Monte Carlo Procedure for the Construction of Complementary Cumulative Distribution Functions for Comparison with the EPA Release Limits for Radioactive Waste Disposal. SAND94-2128. Albuquerque, NM: Sandia National Laboratories.

61. Kaplan, S. 1981. "On the Method of Discrete Probability Distributions in Risk and Reliability Calculations-Application to Seismic Risk Assessment," Risk Analysis. Vol. 1, no. 3, 189-196.

62. U.S. NRC (Nuclear Regulatory Commission). 1990. Severe Accident Risks: An Assessment for Five U.S. Nuclear Power Plants. NUREG-1150. Washington, DC: U.S. Nuclear Regulatory Commission.

63. Helton, J.C. 1993. "Uncertainty and Sensitivity Analysis Techniques for Use in Performance Assessment for Radioactive Waste Disposal," Reliability Engineering and System Safety. Vol. 42, no. 2-3, 327-367. 


\section{UC721 - DISTRIBUTION LIST}

\section{Federal Agencies}

US Department of Energy (6)

Office of Civilian Radioactive Waste Mgmt.

Attn: Deputy Director, RW-2

Associate Director, RW-10/50

Office of Prog. \& Resources Mgmt. Office of Contract Business Mgmt.

Director, RW-22

Analysis \& Verification Division

Associate Director, RW-30

Office of Systems \& Compliance

Associate Director, RW-40

Office of Storage \& Transportation

Director, RW-4/5

Office of Strategic Planning and

International Programs

Office of External Relations

Forrestal Building

Washington, DC 20585

US Department of Energy

Albuquerque Operations Office

Attn: National Atomic Museum Library

P.O. Box 5400

Albuquerque, NM 87185-5400

US Department of Energy

Research \& Waste Management Division

Attn: Director

P.O. Box E

Oak Ridge, TN 37831

US Department of Energy (5)

Carlsbad Area Office

Attn: G. Dials

D. Galbraith

M. McFadden

R. Lark

P.O. Box 3090

J. A. Mewhinney

Carlsbad, NM 88221-3090

US Department of Energy

Office of Environmental Restoration and

Waste Management

Attn: J. Lytle, EM-30

Forrestal Building

Washington, DC 20585-0002
US Department of Energy (3)

Office of Environmental Restoration and Waste Management

Attn: M. Frei, EM-34, Trevion II

Washington, DC 20585-0002

US Department of Energy

Office of Environmental Restoration and Waste Management

Attn: S. Schneider, EM-342, Trevion II

Washington, DC 20585-0002

US Department of Energy (2)

Office of Environment, Safety \& Health

Attn: C. Borgstrom, EH-25

R. Pelletier, EH-231

Washington, DC 20585

US Department of Energy (2)

Idaho Operations Office

Fuel Processing \& Waste Mgmt. Division 785 DOE Place

Idaho Falls. ID 83402

US Environmental Protection Agency (2)

Radiation Protection Programs

Attn: M. Oge

ANR-460

Washington, DC 20460

Tomothy M. Barry

Office of Policy, Planning \& Evaluation

PM 223X U. S. EPA

Washington, DC 20460

US Department of Energy

Rocky Flats Area Office

Attn: T. Lukow

P. O. Box 928

Golden, CO 80402-0928

US Nuclear Regulatory Commission (3)

Division of High Level Waste Management

Attn: Seth Coplan

R. Codell

N. Eisenberg

Mail Stop 4-H-3

Washington, DC 20555 
Boards

Defense Nuclear Facilities Safety Board

Attn: D. Winters

625 Indiana Ave. NW, Suite 700

Washington, DC 20004

Nuclear Waste Technical Review Board (2)

Attn: Chairman

S. J. S. Parry

1100 Wilson Blvd., Suite 910

Arlington, VA 22209-2297

\section{State Agencies}

Attorney General of New Mexico

P.O. Drawer 1508

Santa Fe, NM 87504-1508

Environmental Evaluation Group (3)

Attn: Library

7007 Wyoming NE

Suite F-2

Albuquerque, NM 87109

NM Energy, Minerals, and Natural

Resources Department

Attn: Library

2040 S. Pacheco

Santa Fe, NM 87505

NM Environment Department (3)

Secretary of the Environment

Attn: Mark Weidler

1190 St. Francis Drive

Santa Fe, NM 87503-0968

NM Bureau of Mines \& Mineral Resources

Socorro, NM 87801

NM Environment Department

WIPP Project Site

Attn: P. McCasland

P.O. Box 3090

Carlsbad, NM 88221

\section{Laboratories/Corporations}

Battelle Pacific Northwest Laboratories Attn: R. E. Westerman, MSIN P8-44

Battelle Blvd.

Richland, WA 99352
INTERA, Inc.

Attn: G. A. Freeze

1650 University Blvd. NE, Suite 300

Albuquerque, NM 87102

INTERA,.Inc.

Attn: J. F. Pickens

6850 Austin Center Blvd., Suite 300

Austin, TX 78731

INTERA, Inc.

Attn: W. Stensrud

P.O. Box 2123

Carlsbad, NM 88221

Los Alamos National Laboratory

Attn: B. Erdal, INC-12

P.O. Box 1663

Los Alamos, NM 87544

RE/SPEC, Inc

Attn: Angus Robb

4775 Indian School NE, Suite 300

Albuquerque, NM 87110-3927

RE/SPEC, Inc

Attn: J. L. Ratigan

P.O. Box 725

Rapid City, SD 57709

Tech Reps, Inc. (3)

Attn: J. Chapman (1) Loretta Robledo (2)

5000 Marble NE, Suite 222

Albuquerque, NM 87110

Westinghouse Electric Corporation (5)

Attn: Library

J. Epstein

J. Lee

B. A. Howard

R. Kehrman

P.O. Box 2078

Carlsbad, NM 88221

S. Cohen \& Associates

Attn: Bill Thurber

1355 Beverly Road

McLean, VA 22101

Battelle Northwest

Attn: Pamela Doctor

P. O. Box 999

Richland, WA 99352 
Los Alamos National Laboratory

Analysis and Assessment Division

A-1, MS F600

Attn: M. D. McKay

P. O. Box 1663

Los Alamos, NM 87544

Kenneth T. Bogen

Environmental Sciences Division

Lawrence Livermore National Laboratory

Livermore, CA 94550

David Burmaster

Alceon Corporation

P. O. Box 2669

Harvard Square Station

Cambridge, MA 02239

Idaho National Laboratory

Westinghouse-Idaho Nuclear Co.

Attn: R. Klingler

Mail Stop 3422

P. O. Box 4000

Idaho Falls, ID 83415-3422

Beta Corporation Int.

Attn: E. Bonano

6613 Esther NE

Albuquerque, NM 87109

Ecodynamics

Attn: P. Roache

P. O. Box 9229

Albuquerque, NM 87119-9229

A. E. Van Luik

The Valley Bank Center

101 Convention Center Drive

Las Vegas, NV 89109

Center for Nuclear Waste Regulatory Analysis (CNWRA)

Southwest Research Institute

Attn: B. Sagar

P. O. Drawer 28510

6220 Culebra Road

San Antonio, TX 78284

Dr. F. Owen Hoffman

SENES Oak Ridge

102 Donner Drive

Oak Ridge, TN 37830
Dr. Alison Cullen

2125 North 90 th Street

Seattle, WA 98103

\section{National Academy of Sciences, WIPP Panel}

Howard Adler

Oxyrase, Incorporated

7327 Oak Ridge Highway

Knoxville, TN 37931

Bob Andrews

Board of Radioactive Waste Management

GF456

2101 Constitution Ave.

Washington, DC 20418

Rodney C. Ewing

Department of Geology

University of New Mexico

Albuquerque, NM 87131

Charles Fairhurst

Department of Civil and Mineral Engineering

University of Minnesota

500 Pillsbury Dr. SE

Minneapolis, MN 55455-0220

B. John Garrick

PLG Incorporated

4590 MacArthur Blvd., Suite 400

Newport Beach, CA 92660-2027

Leonard F. Konikow

US Geological Survey

431 National Center

Reston, VA 22092

Carl A. Anderson, Director

Board of Radioactive Waste Management

National Research Council

HA 456

2101 Constitution Ave. NW

Washington, DC 20418

Christopher G. Whipple

ICF Kaiser Engineers

1800 Harrison St., 7th Floor

Oakland, CA 94612-3430 
John O. Blomeke

720 Clubhouse Way

Knoxville, TN 37909

Sue B. Clark

University of Georgia

Savannah River Ecology Lab

P.O. Drawer E

Aiken, SC 29802

Konrad B. Krauskopf

Department of Geology

Stanford University

Stanford, CA 94305-2115

Della Roy

Pennsylvania State University

217 Materials Research Lab

Hastings Road

University Park, PA 16802

David A. Waite

$\mathrm{CH}_{2} \mathrm{M}$ Hill

P.O. Box 91500

Bellevue, WA 98009-2050

Thomas A. Zordon

Zordan Associates, Inc.

3807 Edinburg Drive

Murrysville, PA 15668

\section{Universities}

University of New Mexico

Geology Department

Attn: Library

141 Northrop Hall

Albuquerque, NM 87131

University of Washington

College of Ocean \& Fishery Sciences

Attn: G. R. Heath

583 Henderson Hall, HN-15

Seattle, WA 98195

Terry Reilly

Decision Sciences Department

University of Oregon

Eugene, OR 97403-1208

John Evans

Harvard School of Public Health

665 Huntington Avenue

Boston, MA 02115
F. E. Haskin

Dept. of Chemical and Nuclear Engr.

University of New Mexico

Albuquerque, NM 87131

M. Granger Morgan

Dept. of Engineering and Public Policy

Carnegie-Mellon University

Pittsburgh, PA 15213

Yacov Y. Haimes

Center for Risk Management of Engineering

D111 Thornton Hall

University of Virginia

Charlottsville, VA 22901

Elisabeth Pate-Cornell

Industrial Engineering \& Engineering Mgmt.

Stanford University

Stanford, CA 94305

University of Hawaii at Hilo

Business Administration

Attn: S. Hora

Hilo, HI 96720-4091

Alan Gutjahr

Department of Mathematics

New Mexico Institute of Mining \& Tech.

Socorro, NM 87801

Professor George Apostolakis

Room 24-221

Massachusetts Institute of Technology

Cambridge, MA 02139-4307

Professor H. Christopher Frey

North Carolina State University

Dept. of Civil Engineering

Box 7908

Raleigh, NC 27695

Professor Dale Hattis

Center for Technology, Environment \& Dev.

Clark University

950 Main Street

Worcester, Massachusetts 01610

Thomas E. McKone

School of Public Health

University of California

Berkeley, CA 94720-7360 


\section{Libraries}

Thomas Brannigan Library

Attn: D. Dresp

106 W. Hadley St.

Las Cruces, NM 88001

Government Publications Department

Zimmerman Library

University of New Mexico

Albuquerque, NM 87131

New Mexico Junior College

Pannell Library

Attn: R. Hill

Lovington Highway

Hobbs, NM 88240

New Mexico State Library

Attn: N. McCallan

325 Don Gaspar

Santa Fe, NM 87503

New Mexico Tech

Martin Speere Memorial Library

Campus Street

Socorro, NM 87810

WIPP Public Reading Room

Carlsbad Public Library

$101 \mathrm{~S}$. Halagueno St.

Carlsbad, NM 88220

\section{Foreign Addresses}

Studiecentrum Voor Kernenergie

Centre d'Energie Nucleaire

Attn: A. Bonne

SCK/CEN Boeretang 200

B-2400 Mol, BELGIUM

Atomic Energy of Canada, Ltd.

Whiteshell Laboratories

Attn: B. Goodwin

Pinawa, Manitoba, CANADA R0E $1 L 0$

Francois Chenevier (2)

ANDRA

Route de Panorama Robert Schumann

B. P. 38

92266 Fontenay-aux-Roses, Cedex

FRANCE
Claude Sombret

Centre d'Etudes Nucleaires de la Vallee Rhone

CEN/VALRHO

S.D.H.A. B.P. 171

30205 Bagnols-Sur-Ceze, FRANCE

Commissariat a L'Energie Atomique

Attn: D. Alexandre

Centre d'Etudes de Cadarache

13108 Saint Paul Lez Durance Cedex

FRANCE

Bundesanstalt fur Geowissenschaften und

Rohstoffe

Attn: M. Langer

Postfach 510153

D-30631 Hannover, GERMANY

Bundesministerium fur Forschung und

Technologie

Postfach 200706

5300 Bonn 2, GERMANY

Institut fur Tieflagerung

Attn: K. Kuhn

Theodor-Heuss-Strasse 4

D-3300 Braunschweig, GERMANY

Gesellschaft fur Anlagen und Reaktorsicherheit (GRS)

Attn: B. Baltes

Schwertnergasse 1

D-50667 Cologne, GERMANY

Shingo Tashiro

Japan Atomic Energy Research Institute

Tokai-Mura, Ibaraki-Ken, 319-11

JAPAN

Netherlands Energy Research Foundation ECN

Attn: J. Prij

3 Westerduinweg

P.O. Box 1

1755 ZG Petten

THE NETHERLANDS

Svensk Karnbransleforsorjning AB

Attn: F. Karlsson

Project KBS (Karnbranslesakerhet)

Box 5864

S-102 48 Stockholm

SWEDEN 
Nationale Genossenschaft fur die Lagerung

Radioaktiver Abfalle (2)

Attn: S. Vomvoris

P. Zuidema

Hardstrasse 73

CH-5430 Wettingen

SWITZERLAND

AEA Technology

Attn: J. H. Rees

D5W/29 Culham Laboratory

Abington, Oxfordshire OX14 3DB

UNITED KINGDOM

AEA Technology

Attn: W. R. Rodwell

044/A31 Winfrith Technical Centre

Dorchester, Dorset DT2 8DH

UNITED KINGDOM

AEA Technology

Attn: J. E. Tinson

B4244 Harwell Laboratory

Didcot, Oxfordshire OX11 ORA

UNITED KINGDOM

Terry Andres

AECL Research

Whiteshell Laboratories

Pinawa, Manitoba ROE 1LO

CANADA

Russell Cheng

University of Kent at Canterbury

Cornwallis Building

Canterbury, Kent, CT2 7NF

UNITED KINGDOM

Christian Ekberg

Chalmers University of Technology

Dept.of Nuclear Chemistry

S-41296 Goteborg

SWEDEN

Sven Erik Magnusson

Lund University

P.O. Box 118

22100 Lund

SWEDEN
Delft University of Technology

Dept. of Mathematics

Attn: Roger Cooke

Julianalaan 132

Delft

THE NETHERLANDS

J. Marivoet

Centre d'Etudes de l'Energie

Nucleaire (CEN/SCK)

Boeretang 200

B-2400 Mol, BELGIUM

Timo Vieno

Technical Research Centre of Finland

(VTT)

Nuclear Energy Laboratory

P. O. Box 208

SF-02151 Espoo, FINLAND

Claudio Pescatore

Division of Radiation Protection \& Waste Mgmt

OECD Nuclear Energy Agency

38, Boulevard Suchet

F-75016 Paris

FRANCE

Tonis Papp

Swedish Nuclear Fuel \& Waste Mgmt. Co.

Box 5864

S 10248 Stockholm

SWEDEN

Alan J. Hooper

UK Nirex Ltd.

Curie Avenue

Harwell, Didcot

Oxfordshire, OX11 ORH

UNITED KINGDOM

Eduard Hofer

Gesellschaft fur Reaktorsicherheit

(GRS) MBH

Forschungsgelande

D-8046 Garching, GERMANY

Andrea Saltelli

Commission of the European Communities

Joint Research Centre of Ispra

I-21020 Ispra (Varese)

ITALY 
Daniel A. Galson

Galson Sciences Ltd.

35, Market Place

Oakham

Leicestershire LE15 6DT

UNITED KINGDOM

Ghislain de Marsily (GXG Chairman)

University Pierre et Marie Curie

Laboratorie de Geologie Applique

4, Place Jussieu

T.26 - 5e etage

75252 Paris Cedex 05

FRANCE

Atomic Energy of Canada, Ltd.

Whiteshell Research Establishment

Attn: D. Wushke

Pinewa, Manitoba ROE 1LO, CANADA

Johan Andersson

Swedish Nuclear Power Inspectorate

Statens Karnkraftinspektion (SKI)

Box 27106

S-102 52 Stockholm

SWEDEN

Professor Jack P. C. Kleijnen

Department of Information Systems

Tillburg University

5000 LE Tilburg

THE NETHERLANDS

Dr. Marion Scott

Department of Statistics

Mathematics Building

University of Glasgow

Glasgow, G12 8QW

SCOTLAND

Performance Assessment Peer Review Panel

G. Ross Heath

College of Ocean \& Fishery Sciences

University of Washington

583 Henderson Hall, HN-15

Seattle, WA 98195

Thomas H. Pigford

Department of Nuclear Engineering

4159 Etcheverry Hall

University of California

Berkeley, CA 94720
Thomas A Cotton

JK Research Associates, Inc. 4429 Butterworth Place NW Washington, DC 20016

Robert J. Budnitz

President, Future Resources Assoc., Inc. 2000 Center Street, Suite 418

Berkeley, CA 94704

C. John Mann

Department of Geology

245 Natural History Bldg.

1301 West Green Street

University of Illinois

Urbana, IL 61801

Frank W. Schwartz

Dept. of Geology and Mineralogy

Ohio State University

Scott Hall

1090 Carmack Rd.

Columbus, $\mathrm{OH} 43210$

\begin{tabular}{lll}
$\underline{\text { MS }}$ & $\underline{\text { Org. }}$ & \multicolumn{1}{l}{ Internal } \\
1324 & 6115 & P. B. Davies \\
1320 & 6719 & E. J. Nowak \\
1322 & 6121 & J. R. Tillerson \\
1328 & 6749 & D. R. Anderson \\
1328 & 6749 & M. E. Fewell \\
1328 & 6749 & G. K. Froehlich \\
1328 & 6741 & H. N. Jow \\
1328 & 6741 & J. C. Helton (10) \\
1328 & 6741 & M. S. Tierney \\
1328 & 6741 & K. E. Economy \\
1335 & 6705 & M. Chu \\
1341 & 6811 & A. L. Stevens \\
1341 & 6747 & D. R. Schafer \\
1341 & 6748 & J. T. Holmes \\
1341 & 6821 & P. N. Swift \\
1345 & 6751 & K. W. Larson \\
1395 & 6700 & P. Brewer \\
1395 & 6800 & L. Shephard \\
1395 & 6707 & M. Marietta \\
1395 & 6841 & V. H. Slaboszewicz \\
& & \\
1330 & 6752 & C. B. Michaels (2) \\
1330 & 6752 & NWM Library (20) \\
9018 & $8523-2$ & Central Technical Files \\
0899 & 4414 & Technical Library (5) \\
0619 & 12615 & Print Media \\
0100 & $7613-2$ & Document Processing (2) \\
& & for DOE/OSTI \\
& &
\end{tabular}


